\title{
Potential Energy Savings Due to Phase Change Material in a Building Wall Assembly: An Examination of Two Climates
}

March 2012

Prepared by

Kenneth Childs

Therese Stovall 


\title{
DOCUMENT AVAILABILITY
}

Reports produced after January 1, 1996, are generally available free via the U.S. Department of Energy (DOE) Information Bridge.

Web site http://www.osti.gov/bridge

Reports produced before January 1, 1996, may be purchased by members of the public from the following source.

\author{
National Technical Information Service \\ 5285 Port Royal Road \\ Springfield, VA 22161 \\ Telephone 703-605-6000 (1-800-553-6847) \\ TDD 703-487-4639 \\ Fax 703-605-6900 \\ E-mail info@ntis.gov \\ Web site http://www.ntis.gov/support/ordernowabout.htm
}

Reports are available to DOE employees, DOE contractors, Energy Technology Data Exchange (ETDE) representatives, and International Nuclear Information System (INIS) representatives from the following source.

Office of Scientific and Technical Information

P.O. Box 62

Oak Ridge, TN 37831

Telephone 865-576-8401

Fax 865-576-5728

E-mail reports@osti.gov

Web site http://www.osti.gov/contact.html

This report was prepared as an account of work sponsored by an agency of the United States Government. Neither the United States Government nor any agency thereof, nor any of their employees, makes any warranty, express or implied, or assumes any legal liability or responsibility for the accuracy, completeness, or usefulness of any information, apparatus, product, or process disclosed, or represents that its use would not infringe privately owned rights. Reference herein to any specific commercial product, process, or service by trade name, trademark, manufacturer, or otherwise, does not necessarily constitute or imply its endorsement, recommendation, or favoring by the United States Government or any agency thereof. The views and opinions of authors expressed herein do not necessarily state or reflect those of the United States Government or any agency thereof. 
ORNL/TM-2012/6

Energy and Transportation Science Division

\title{
POTENTIAL ENERGY SAVINGS DUE TO PHASE CHANGE MATERIAL IN A BUILDING WALL ASSEMBLY: AN EXAMINATION OF TWO CLIMATES
}

\author{
Kenneth Childs \\ Therese Stovall
}

Date Published: March 2012

Prepared by

OAK RIDGE NATIONAL LABORATORY

Oak Ridge, Tennessee 37831-6283

managed by

UT-BATTELLE, LLC

for the

U.S. DEPARTMENT OF ENERGY

under contract DE-AC05-00OR22725 



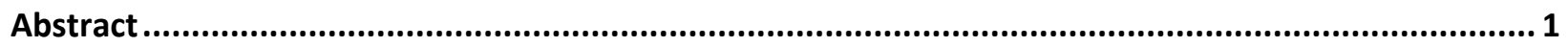

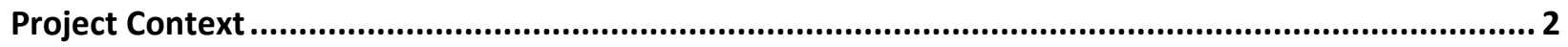

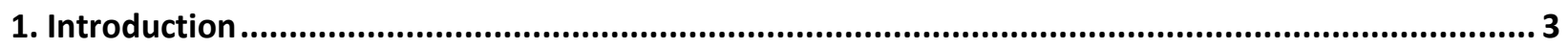

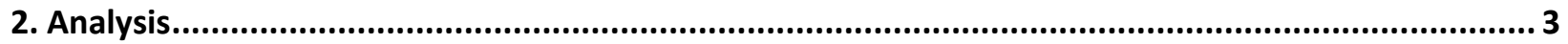

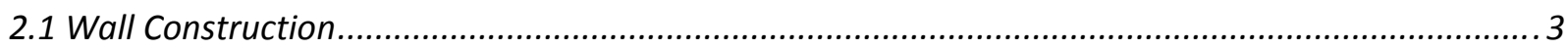

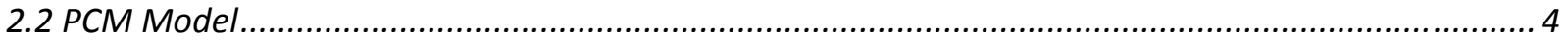

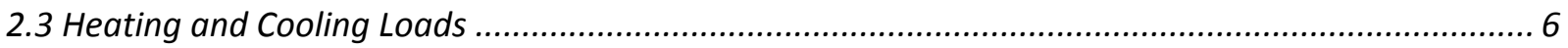

2.4 Modeling Approach and Tools ................................................................................................ 7

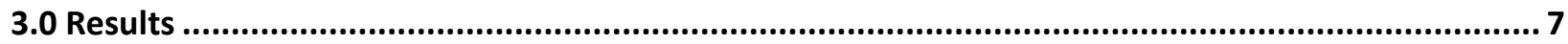

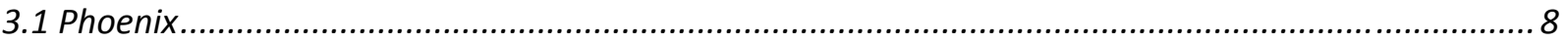

3.1.1 Phase Change Temperature and Load Reduction............................................................ 8

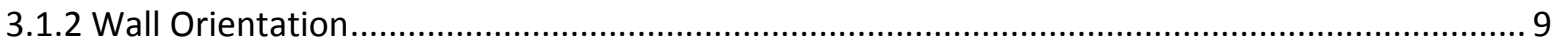

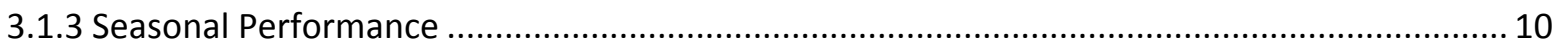

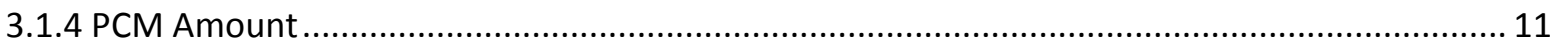

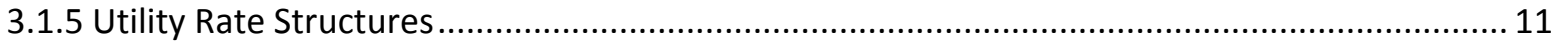

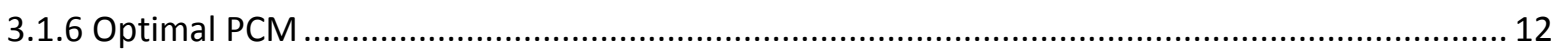

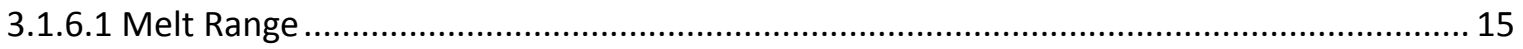

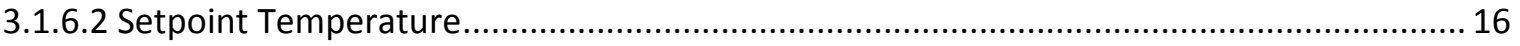

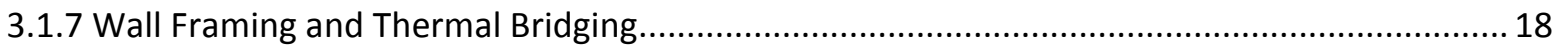

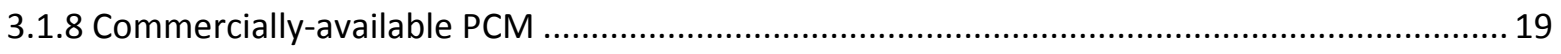

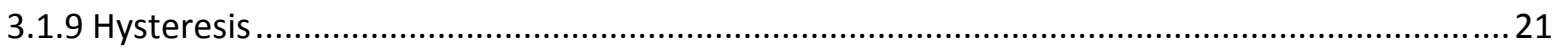

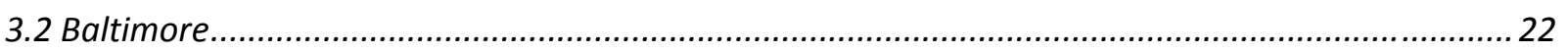

3.2.1 Phase Change Temperature and Load Reductions .......................................................... 22

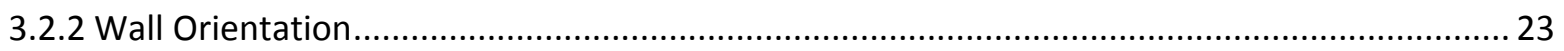

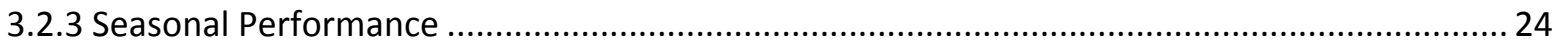

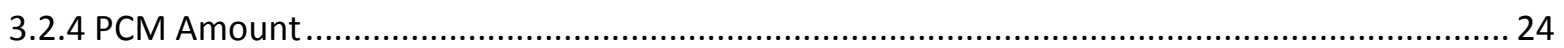

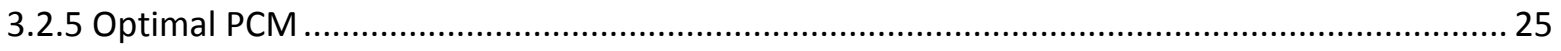

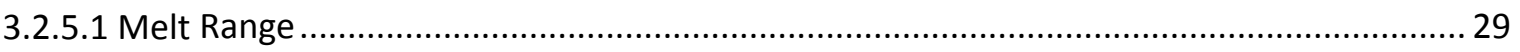

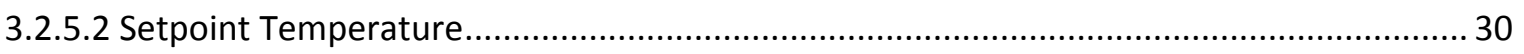

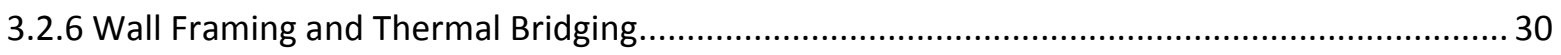

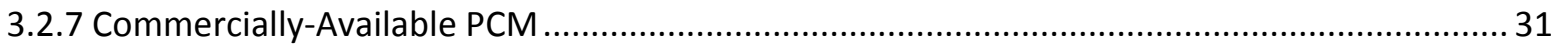

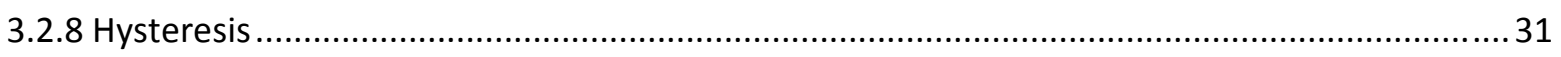

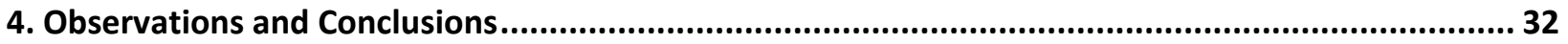

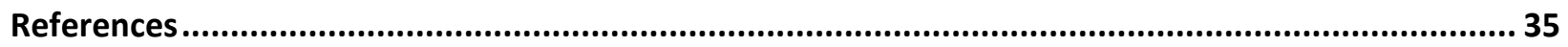

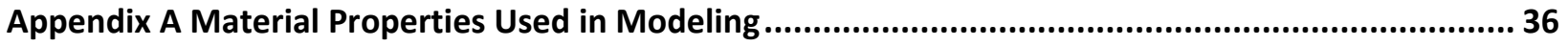

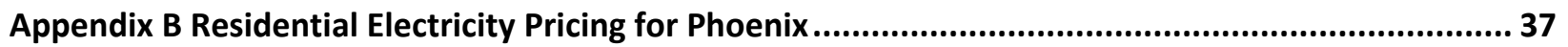




\begin{abstract}
Phase change material (PCM), placed in an exterior wall, alters the temperature profile within the wall and thus influences the heat transport through the wall. This may reduce the net energy transport through the wall via interactions with diurnal temperature swings in the external environment or reduce the electricity needed to meet the net load through the wall by shifting the time of the peak load to a time when the cooling system operates more efficiently. This study covers a broad range of parameters that can influence the effectiveness of such a merged thermal storage-thermal insulation system. These parameters included climate, PCM location within the wall, amount of PCM, midpoint of the PCM melting and freezing range relative to the indoor setpoint temperature, temperature range over which phase change occurs, and the wall orientation. Two climates are investigated using finite difference and optimization analyses: Phoenix and Baltimore, with two utility rate schedules. Although potential savings for a PCM with optimized properties were greater when the PCM was concentrated near the inside wall surface, other considerations described here lead to a recommendation for a full-thickness application. An examination of the temperature distribution within the walls also revealed the potential for this system to reduce the amount of energy transported through the wall framing. Finally, economic benefits can exceed energy savings when time-of-day utility rates are in effect, reflecting the value of peak load reductions for the utility grid.
\end{abstract}




\section{Project Context}

In light of new material developments, and a new world energy and economic environment, the U.S. Department of Energy has decided to reconsider some approaches to building energy management that had previously been considered to be of limited benefit. Therefore, a suite of three analyses was prepared to evaluate potential applications of phase change materials in building envelopes. The first analysis asks the question, 'What properties should a PCM have, and where should it be located, in order to optimize energy and/or economic savings?' The second analysis evaluated, and improved, the toolset available for PCMs within the whole building modeling framework. The third analysis reviews the current costs of PCMs and describes the potential payback that could be achieved under theoretical circumstances.

This report describes the study that examined one particular wall design, and determined the maximum technical potential for PCM energy savings for two locations.

The other two portions of the work are described in:

Tabares-Velasco, P. C., C. Christensen, et al. (2012). Simulated Peak Reduction and Energy Savings of Residential Building Envelope with Phase Change Materials. ASHRAE Transactions. San Antonio, TX, xx. under review

Tabares-Velasco, P. C., C. Christensen, et al. (2012). "Verification and Validation of EnergyPlus Phase Change Material Model for Opaque Wall Assemblies." Building and Environment (under review)

Tabares-Velasco, P. C. and B. Griffith "Diagnostic test cases for verifying surface heat transfer algorithms and boundary conditions in building energy simulation programs." Journal of Building Performance Simulation: 1-18.

Kosny, J., Shukla, N., and Fallahi, A., Cost Analysis of Simple PCMEnhance Buildng Envelopes in Southernn U.S. Cimates, Building America Program, Fraunhofer CSE, Cambridge MA, January, 2012 


\section{Introduction}

Energy storage in buildings, and phase change material (PCM) energy storage in particular, have been studied for a number of years. The goal has typically been to buffer the indoor conditioned space against large swings in outdoor temperature, thus reducing the energy required to maintain comfort. Some of the earlier efforts focused on placing the PCM in direct contact with the conditioned space by incorporating the energy storage within the gypsum drywall.[1-4] This proved effective for storing heat from incident solar energy and in reducing cooling loads for those cases where free night-time ventilation was available to freeze the PCM during unoccupied hours.[5-6] One of the primary challenges for this application was ensuring adequate heat transport between the PCM and the conditioned space.

Another concept was proposed a few years ago that incorporates the PCM energy storage within the wall insulation itself.[7-9] This application is counter-intuitive, because it deliberately inhibits energy transport between the PCM and both the conditioned space and the exterior environment. However, this PCM location alters the temperature profile within the wall, and thus influences the heat transport through the wall. This can reduce the net energy transported through the interior wall surface or change the time when the energy crosses that boundary. A time delay can prove valuable in economic terms if time-of-day rates are available and in energy terms if the HVAC system operates more efficiently at the time of the shifted load.

This study investigates the impact of PCM placed in the exterior walls of a building on the building's heating and cooling loads. The only loads that are addressed are those due to heat transfer through the opaque portions of the walls. Loads due to windows, air leakage or internal heat sources are not addressed. Several heating and cooling loads are addressed, but the the load of primary interest is the amount of electricity required to meet the annual cooling needs. The goal is to reduce the total electricity required for cooling by identifying optimal PCM characteristics for specific applications. The parameters varied in this study include (1) climate, (2) the location of the PCM in the wall, (3) the amount of PCM, (4) the midpoint of the PCM melting and freezing range relative to the indoor setpoint temperature, (5) the temperature range over which phase change occurs, and (6) wall orientation. Two climates are investigated: Phoenix and Baltimore. Two utility rate schedules were evaluated for Phoenix. In addition to the parametric evaluation over these six variables, more limited investigations were directed toward: (1) the impact of framing within the wall, (2) the performance of a specific PCM with lab-measured characteristics and (3) the impact of hysteresis.

The type of PCM being investigated is a micro-encapsulated paraffin that is distributed in a blown-in cellulose insulation. These results may also provide useful information for concentrated forms of PCM because the location of the PCM within the wall was varied down to very small thicknesses.

\section{Analysis}

\subsection{Wall Construction}

The wall being studied, shown in Figure 1, consists of the following layers from inside to outside: 0.5" gypsum, 5.5" cellulose, 0.5 " plywood siding. Material properties for the materials making up the wall are 
given in Appendix A. The cellulose layer can have PCM uniformly distributed throughout the full thickness or concentrated in thinner layers spanning only a portion of the cellulose thickness. For example, experiments have been performed with the cellulose-PCM mixture in one half of a wall, separated by a thin film from the other half of the cavity filled with plain cellulose.[10]

Most of the analyses performed are for the clear wall (i.e., the impact of thermal bridges were not considered.) This was done for expediency since it allowed the use of one-dimensional rather than twodimensional models. However, results are also presented that directly address the performance of PCM in a wall with bridges.

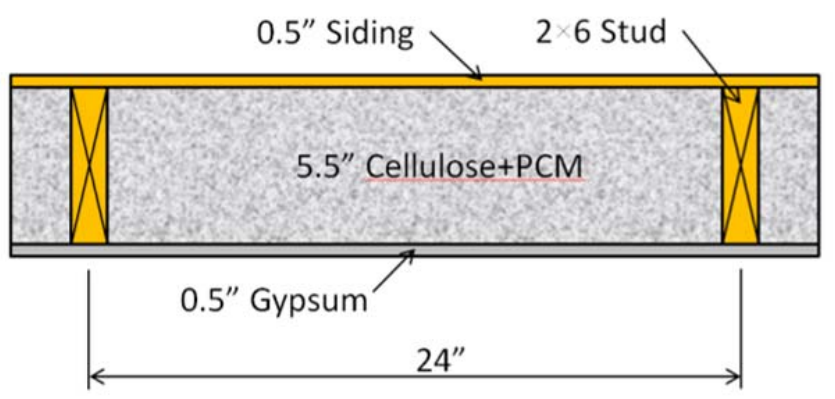

Figure 1 Cross section of wall

\subsection{PCM Model}

An idealized shape is used for the PCM melt curve as shown in Figure 2. It is assumed that the melt curve is piecewise linear with $80 \%$ of the phase change occurring over the middle half of the melt range. (The melt range spans the temperature at which the PCM starts to melt to the temperature at which melting is complete.) This assumed behavior is somewhat arbitrary, but it is a reasonable representation of the general shape of the melt curve for many PCMs. Using this generic shape, a large family of melt curves can be defined by specifying the midpoint of the melt range and the width of the melt range. This idealized melt curve is used in most of the calculations, but an actual PCM with laboratory-determined melt characteristics is also investigated.

For most of these analyses, is assumed that the phase change occurs over the same temperarture range for freezing as for melting (i.e., the PCM does not exhibit hysteresis.) 


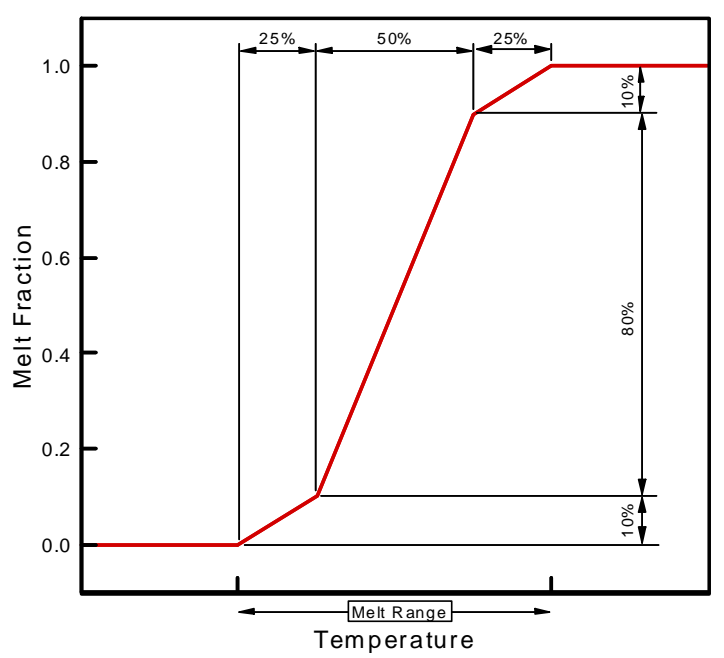

Figure 2 Idealized PCM melt curve

The amount of PCM distributed in the cellulose insulation is quantified as the mass of PCM per unit surface area of wall, $m_{P C M}^{\prime \prime}$. This measure of the mass of PCM is used along with the thickness of cellulose containing the PCM, $t$, to calculate a virtual PCM density (i.e., the mass of PCM per unit volume of cellulose.)

$$
\rho_{P C M}^{*}=\frac{m_{P C M}^{\prime \prime}}{t}
$$

The effective properties of the cellulose/PCM mixture (density, specific heat and latent heat) are then calculated using the following relationships.

$$
\begin{gathered}
\rho_{\text {mix }}=\rho_{\text {cell }}+\rho_{P C M}^{*} \\
c_{p_{-} \text {mix }}=\frac{\rho_{\text {cell }} \times c_{p_{\text {cell }}}+\rho_{P C M}^{*} \times c_{p_{-} P C M}}{\rho_{\text {mix }}} \\
L_{\text {mix }}=\frac{L_{P C M} \times \rho_{P C M}^{*}}{\rho_{\text {mix }}}
\end{gathered}
$$

The conductivity of the cellulose/PCM mixture is assumed to be the same as that of the cellulose. This has been experimentally shown to be a reasonable assumption for small amounts of PCM added to the cellulose. [9] However at some point the addition of more PCM will begin to have an influence on the thermal conductivity, but that possibility is not considered in this study. 
Except for the analysis focusing on the optimal amount of PCM to use, all analysis used $2.4 \mathrm{~kg} / \mathrm{m}^{2}$ of PCM of wall area. This has previously been identified as the maximum amount that can be held in suspension in loose-fill cellulose insulation and was therefore chosen to help determine the maximum potential benefit of this PCM wall system.[11]

\subsection{Heating and Cooling Loads}

There are several heating and cooling loads that may be of interest.

1. The peak heating load is the maximum instantaneous rate of heat flow from the interior air to the wall during the entire year. This load has implications in the sizing of heating equipment.

2. The annual heating load is the cumulative heat flow from the interior air to the wall during the year. In the model the annual heating load is calculated by integrating the heat flow from the interior air to the wall over the year excluding those times when heating is not required (as indicated by an interior air temperature in the float range above the heating setpoint.)

3. The peak cooling load is the maximum instantaneous rate of heat flow from the wall to the interior air during the entire year. This load has implications in the sizing of cooling equipment.

4. The annual cooling load is the cumulative heat flow from the wall to the interior air during the year. In the model the annual cooling load is calculated by integrating the heat flow from the wall to the interior air over the year excluding those times when cooling is not required (as indicated by an interior air temperature in the float range below the cooling setpoint.)

5. The annual cooling electricity use is the amount of electricity used by the cooling system to meet the cooling load. This is a function of the efficiency of the cooling system. A plot of energy efficiency ratio (EER) versus ambient temperature for the air conditioning unit used in this study is given in Figure 3.

6. The annual cooling cost is the cost of the electricity needed to meet the annual cooling load. This is of interest if the utility offers time-of-day or peak-load-based pricing for electricity.

The impact of PCM on all of the cooling/heating loads listed above is examined, but the bulk of the investigation focuses on PCM's impact on the annual cooling electricity use.

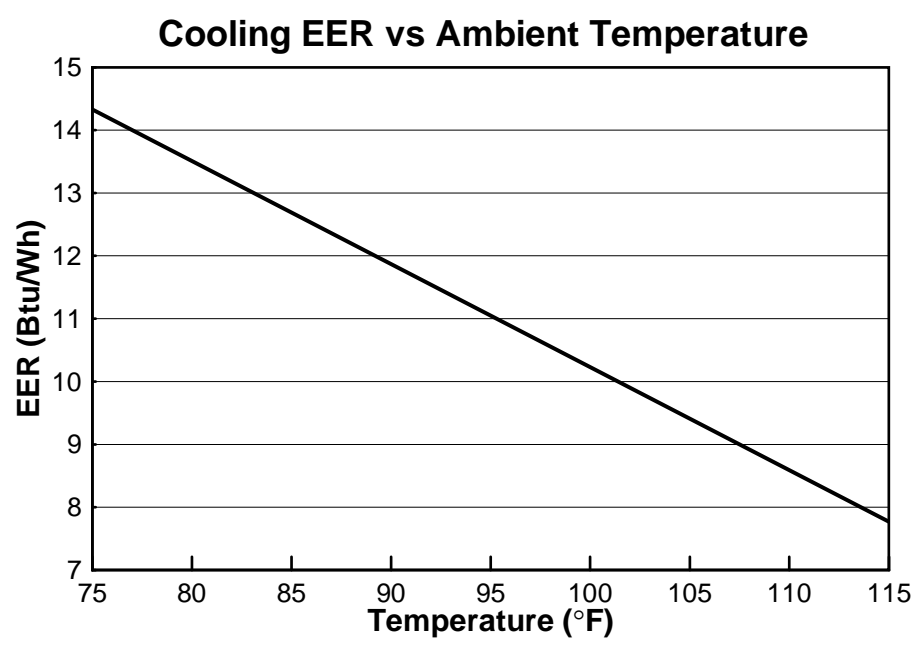

Figure 3 Air conditioner efficiency 


\subsection{Modeling Approach and Tools}

To explore the impact that PCM has on the thermal performance of a wall, a detailed one- or twodimensonal model of a wall of interest is constructed using the HEATING 8 code. HEATING 8 is the latest in a long line of general-purpose heat transfer codes developed at Oak Ridge National Laboratory. The primary enhancement over the previous version [12] is the inclusion of an enhanced phase change modeling capability. The HEATING model is then used to perform one-year-long transient analyses with and without the inclusion of the PCM.

Exterior boundary conditions are obtained from TMY3 weather files. Since the goal is to indentify general behavior or trends rather than to accurately predict the performance of a specific building, the external boundary condition can be somewhat simplified. The exterior boundary conditions on the wall used in this study consist of:

1. Solar flux on an unshaded vertical surface with an absorptivity of 0.6.

2. Radiation to the sky with a view factor of 0.5 and an emissivity of 1.0.

3. Convection from the surface to ambient temperature with a constant wind speed of $7.5 \mathrm{mph}$ (heat transfer coefficient of $22.3 \mathrm{~W} / \mathrm{m}^{2}-\mathrm{K}$ from ASHRAE Handbook.)

The solar flux is taken from the weather file and is dependent on the wall orientation.

It is assumed the wall is air-tight, that is, neither air nor moisture transport through the wall is modeled. The interior boundary condition is natural convection from the surface to the indoor air temperature (heat transfer coefficient of $8.34 \mathrm{~W} / \mathrm{m}^{2}-\mathrm{K}$ from ASHRAE Handbook.) The heating and cooling setpoints are $20^{\circ} \mathrm{C}$ and $25^{\circ} \mathrm{C}$, respectively. It is assumed that the heating and cooling systems can exactly match the instantaneous loads so that the indoor air temperature will never exceed the cooling setpoint or go below the heating setpoint. The interior air temperature can float between the heating and cooling setpoints as the interior air mass is heated or cooled by heat transfer from the inside wall surface to/from the air. Internal loads are not considered.

The HEATING code has also been coupled with an optimization program [11] to allow the determination of the PCM melt properties (midpoint and width of melt range) that minimize a heating or cooling load of interest for a given PCM location and amount.

\subsection{Results}

A number of parameters, including midpoint melt temperature, wall orientation, season, amount of $\mathrm{PCM}$, and rate structure, were systematically varied to explore their impact on the technical savings potential for the PCM wall system, as shown in Table 1. During this part of the analysis, all variables other than the variable of interest were held constant. The nominal case includes $2.4 \mathrm{~kg} / \mathrm{m}^{2}$ of PCM uniformly distributed through the full thickness of the cellulose. This gives the wall a latent heat capacity of $408 \mathrm{~kJ}$ per square meter of wall surface area. The width of the melt range was set to $4^{\circ} \mathrm{C}$. The initial analysis found the optimal midpoint of the melt range to be $27^{\circ} \mathrm{C}$ in Phoenix, and that value was used for the other Phoenix single parameter analyses. In Baltimore, the optimal midpoint was $25^{\circ} \mathrm{C}$, and that value was used in the other Baltimore single parameter analyses. 
Table 1 Analysis Structure

\begin{tabular}{|c|c|c|c|c|c|c|c|c|}
\hline \multirow{2}{*}{$\begin{array}{l}\text { Analysis } \\
\text { Stage }\end{array}$} & \multicolumn{2}{|c|}{ PCM Melt Range $\left({ }^{\circ} \mathrm{C}\right)$} & \multirow{2}{*}{$\begin{array}{l}\text { Amount } \\
\text { of PCM } \\
\left(\mathrm{kg} / \mathrm{m}^{2}\right)\end{array}$} & \multirow{2}{*}{$\begin{array}{c}\text { Location } \\
\text { within } \\
\text { Wall }\end{array}$} & \multirow{2}{*}{$\begin{array}{c}\text { Wall } \\
\text { Orientation }\end{array}$} & \multirow{2}{*}{$\begin{array}{l}\text { Time } \\
\text { Period }\end{array}$} & \multirow{2}{*}{$\begin{array}{c}\text { Rate } \\
\text { Structure }\end{array}$} & \multirow{2}{*}{ Section(s) } \\
\hline & Midpoint & Width & & & & & & \\
\hline \multirow{5}{*}{$\begin{array}{c}\text { Single } \\
\text { Parameter } \\
\text { Evaluation }\end{array}$} & Varied & 4 & 2.4 & $\begin{array}{c}\text { Full } \\
\text { Thickness }\end{array}$ & South & Annual & Fixed & $\begin{array}{l}3.1 .1 \\
3.2 .1 \\
\end{array}$ \\
\hline & $\begin{array}{l}27 \text { Phoenix, } \\
25 \text { Baltimore }\end{array}$ & 4 & 2.4 & $\begin{array}{c}\text { Full } \\
\text { Thickness } \\
\end{array}$ & All four & Annual & Fixed & $\begin{array}{l}3.1 .2 \\
3.2 .2 \\
\end{array}$ \\
\hline & $\begin{array}{l}27 \text { Phoenix, } \\
25 \text { Baltimore }\end{array}$ & 4 & 2.4 & $\begin{array}{c}\text { Full } \\
\text { Thickness } \\
\end{array}$ & West & Monthly & Fixed & $\begin{array}{l}3.1 .3 \\
3.2 .3 \\
\end{array}$ \\
\hline & $\begin{array}{l}27 \text { Phoenix, } \\
25 \text { Baltimore }\end{array}$ & 4 & Varied & $\begin{array}{c}\text { Full } \\
\text { Thickness }\end{array}$ & All four & Annual & Fixed & $\begin{array}{l}3.1 .4 \\
3.2 .4\end{array}$ \\
\hline & 27 Phoenix & 4 & 2.4 & $\begin{array}{c}\text { Full } \\
\text { Thickness }\end{array}$ & All four & Annual & $\begin{array}{c}\text { Time of } \\
\text { Day }\end{array}$ & 3.1 .5 \\
\hline $\begin{array}{l}\text { Optimization } \\
\text { of Properties }\end{array}$ & Varied & Varied & 2.4 & Varied & All four & Annual & Fixed & $\begin{array}{l}3.1 .6 \\
3.2 .5 \\
\end{array}$ \\
\hline $\begin{array}{l}\text { Thermal } \\
\text { Bridging }\end{array}$ & Optimal & Optimal & 2.4 & Varied & All four & Annual & Fixed & $\begin{array}{l}3.1 .7 \\
3.2 .6\end{array}$ \\
\hline $\begin{array}{l}\text { Selected } \\
\text { Real PCM }\end{array}$ & Figure 19 & Figure 19 & 2.4 & Varied & All four & Annual & Fixed & $\begin{array}{l}3.1 .8 \\
3.2 .7 \\
\end{array}$ \\
\hline Hysteresis & Figure 22 & Figure 22 & 2.4 & $\begin{array}{c}\text { Full } \\
\text { Thickness } \\
\end{array}$ & West & Annual & Fixed & $\begin{array}{l}3.1 .9 \\
3.2 .8 \\
\end{array}$ \\
\hline
\end{tabular}

\subsection{Phoenix}

\subsubsection{Phase Change Temperature and Load Reduction}

The initial climate investigated is Phoenix, Arizona. For a south-facing wall the percent reductions in various loads as compared to performance without PCM were calculated for the different midpoint melt temperatures. The results are shown in Figure 4. The melt midpoints that produce the maximum reduction in the loads are at distinctly different values. The maximum reduction in annual peak heating load ("Heating Peak" in Fig. 4) occurs at a melt midpoint temperature well below the heating setpoint. The maximum reduction in annual cumulative heating load ("Heating Annual") occurs at a melt midpoint temperature near the heating setpoint. The maximum reduction in annual cumulative cooling load ("Cooling Annual") occurs at a melt midpoint temperature near the cooling setpoint. The maximum reduction in annual cumulative cooling electricity use ("Cooling Electricity") occurs at a melt midpoint temperature slightly above the cooling setpoint. The maximum reduction in the annual peak cooling load ("Cooling Peak") occurs at a melt midpoint temperature well above the cooling setpoint.

The analysis shows that the active temperature range for the PCM must be selected to serve during either the cooling or heating season. It is evident that the midpoint of the PCM melt range must be selected to target the load of primary interest. For this study, the electricity needed to meet the cooling load is of primary interest. 


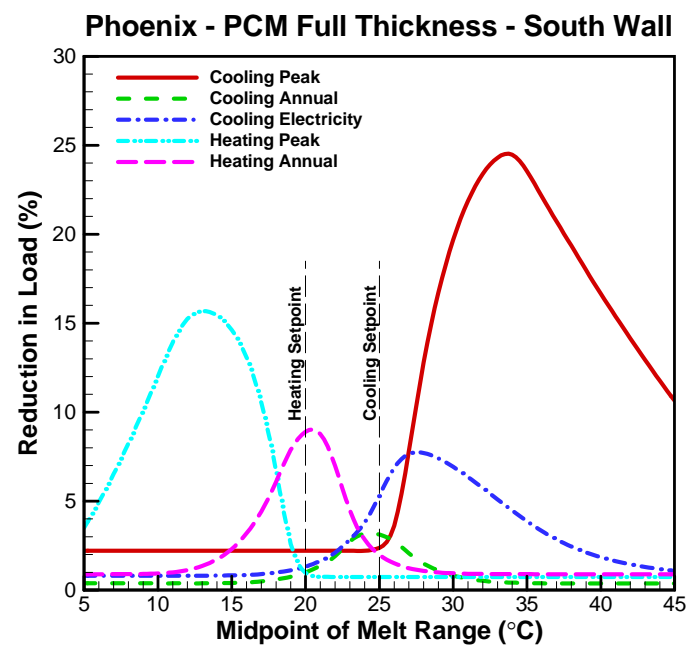

Figure 4 Impact of Melt Midpoint on Heating/Cooling Loads - South Wall, PCM Full Thickness, 2.4 $\mathrm{kg} / \mathrm{m}^{2}, 4^{\circ} \mathrm{C}$ Melt Range

\subsubsection{Wall Orientation}

Figure 5 shows how the reduction in cooling electricity in percent (left) and in kWh per square meter of wall area (right) varies as a function of the midpoint of the melt range for four wall orientations. For all four orientations, the peak reduction in cooling electricity occurs at a melt midpoint of approximately $27^{\circ} \mathrm{C}$, which is $2^{\circ} \mathrm{C}$ above the assumed cooling setpoint temperature. Figure 6 gives the annual cooling electricity use with and without PCM (left) and the cooling energy savings due to the PCM (right) for a melt midpoint of $27^{\circ} \mathrm{C}$. The west wall followed by the south wall have the greatest potential to reduce cooling electricity use due to the PCM. The north wall has the potential to reduce cooling electricity use about the same percent as the south wall, but due to a smaller total cooling load the north wall's potential to reduce electricity use is only about half that of the west or south wall. The potential for cooling electricity savings from PCM in the east wall is also about half that in the west and south walls. 

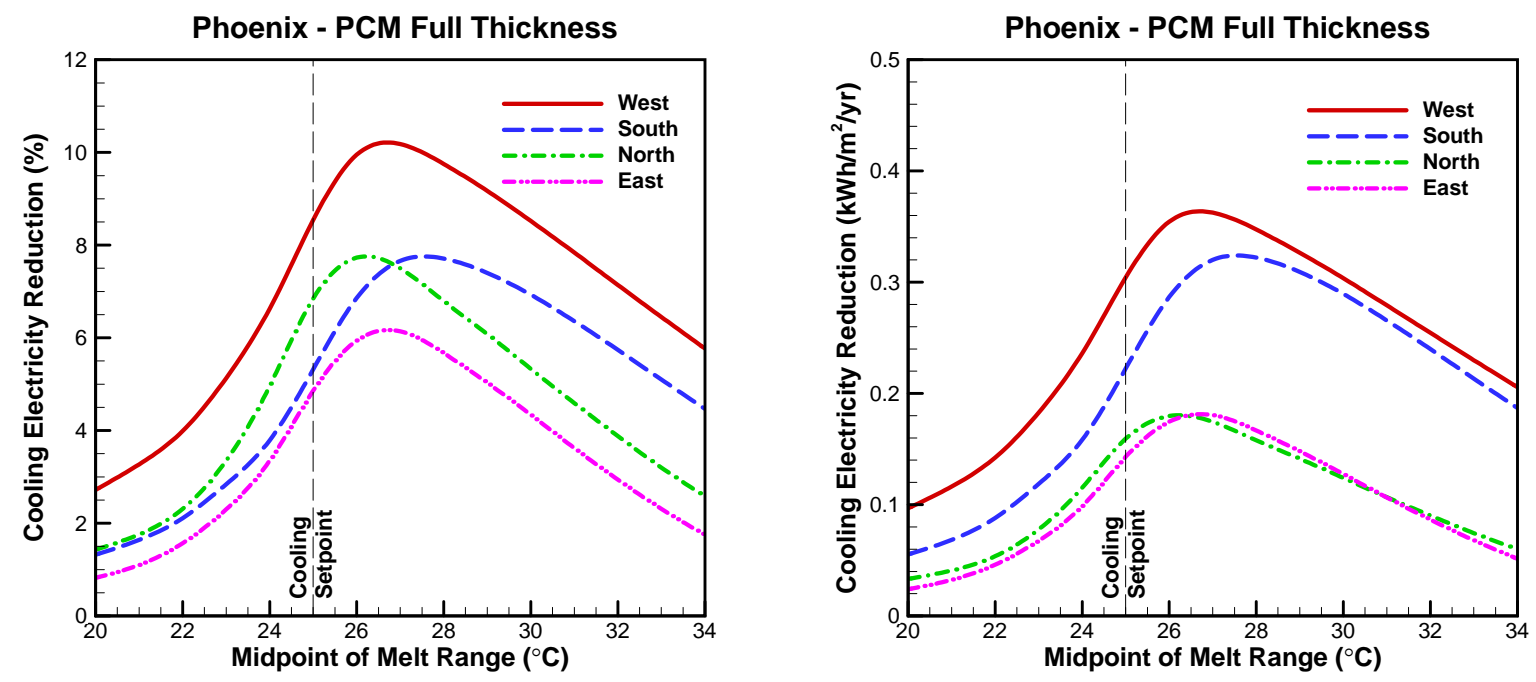

Figure 5 Impact of Wall Orientation - PCM Full Thickness, $2.4 \mathrm{~kg} / \mathrm{m}^{2}, 4^{\circ} \mathrm{C}$ Melt Range
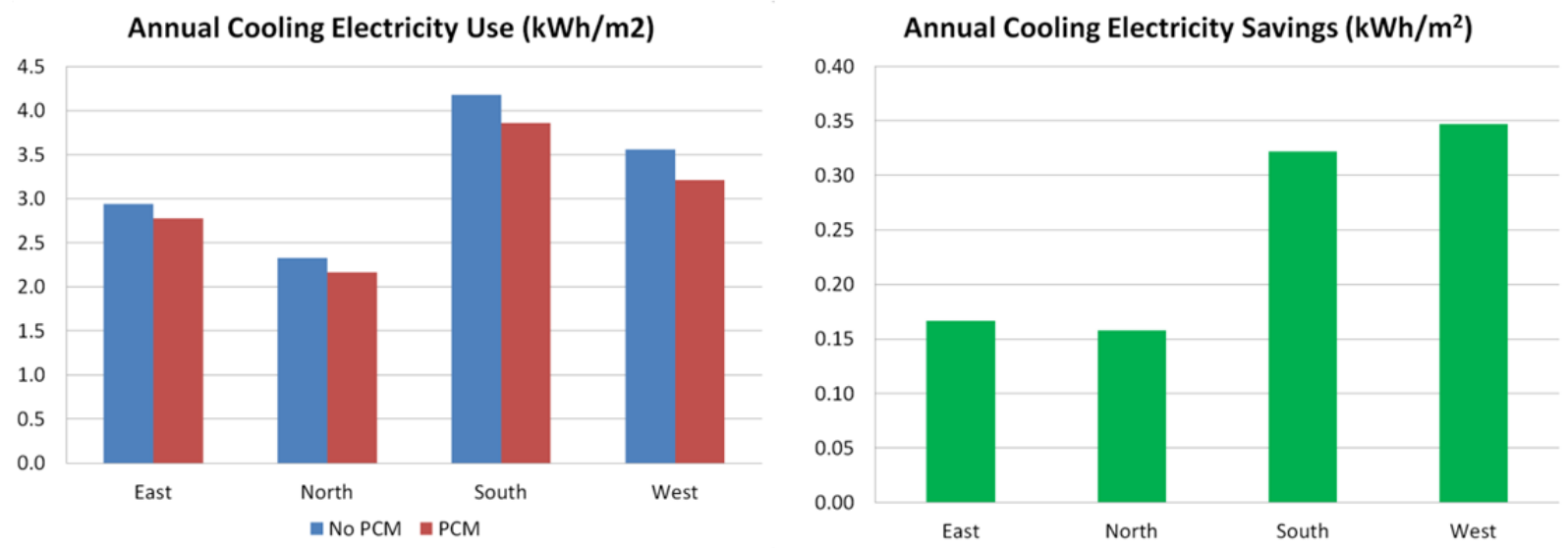

Figure 6 Annual Cooling Electricity Use (L) and Savings (R) - PCM Full Thickness, $2.4 \mathrm{~kg} / \mathrm{m}^{2}, 27^{\circ} \mathrm{C}$ Melt Midpoint, $4^{\circ} \mathrm{C}$ Melt Range

\subsubsection{Seasonal Performance}

Because of variations in ambient conditions throughout the year the ability of the PCM to reduce the cooling electricity also exhibits a seasonal dependence. To illustrate this seasonal variation a west-facing wall is examined. The midpoint of the melt range is set to $27^{\circ} \mathrm{C}$ since that optimizes the effective of the PCM (see Figure 5.) Figure 7 shows the impact that PCM has on the cooling electricity use by month in percent (left) and in $\mathrm{kWh} / \mathrm{m}^{2}$ (right). This figure shows that the PCM produces large percentage reductions in cooling electricity for months where the cooling load is small, but the most significant energy savings occur in months when it is most needed, that is, when the cooling load is large. Note that there is no cooling load for December. 

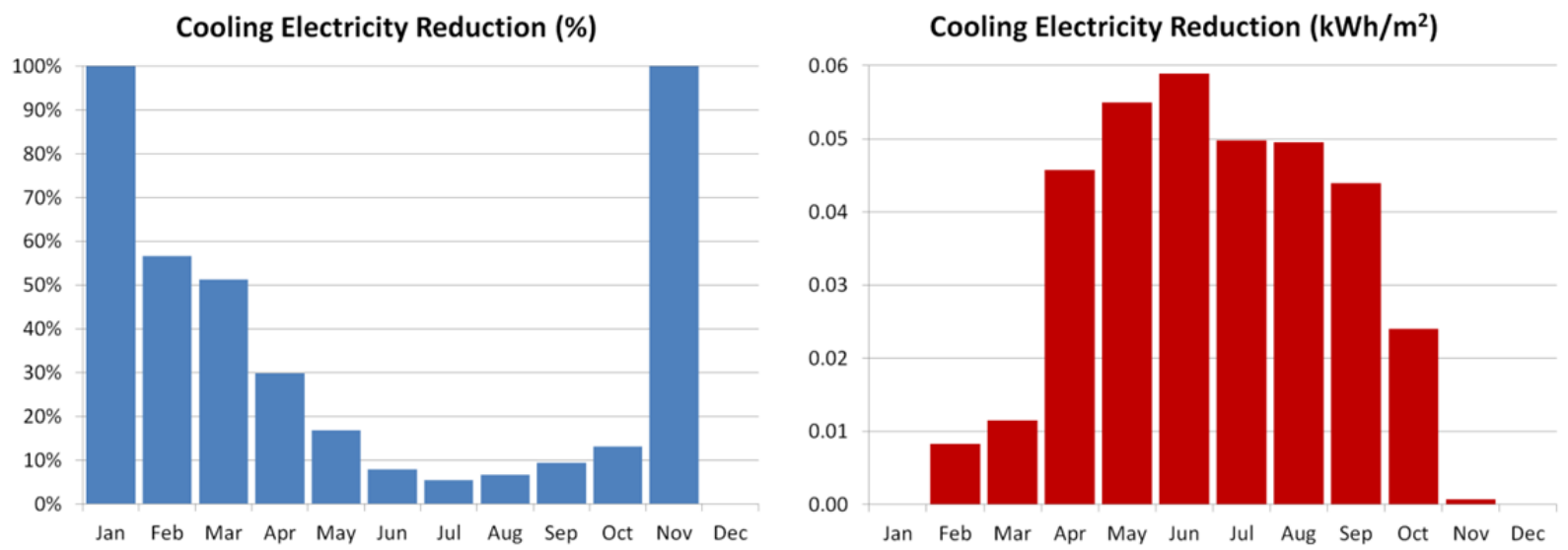

Figure 7 Cooling electricity reduction due to PCM - PCM full thickness, west wall, $27^{\circ} \mathrm{C}$ melt midpoint, $4^{\circ} \mathrm{C}$ melt range,

\subsubsection{PCM Amount}

The results just presented all used $2.4 \mathrm{~kg}$ of PCM per square meter of wall surface area. Figure 8 shows the reduction in cooling electricity use as a function of the mass of PCM. For small amounts of PCM the reduction in cooling electricity use changes approximately linearly with the mass of PCM, but there is diminishing savings for incremental increases in PCM beyond some point. The use of $2.4 \mathrm{~kg} / \mathrm{m}^{2}$ appears to be reasonable, but the optimal amount might be slightly smaller amount since the curves have begun to flatten out. This issue needs to be revisited when mature manufacturing costs are known for the PCM system.
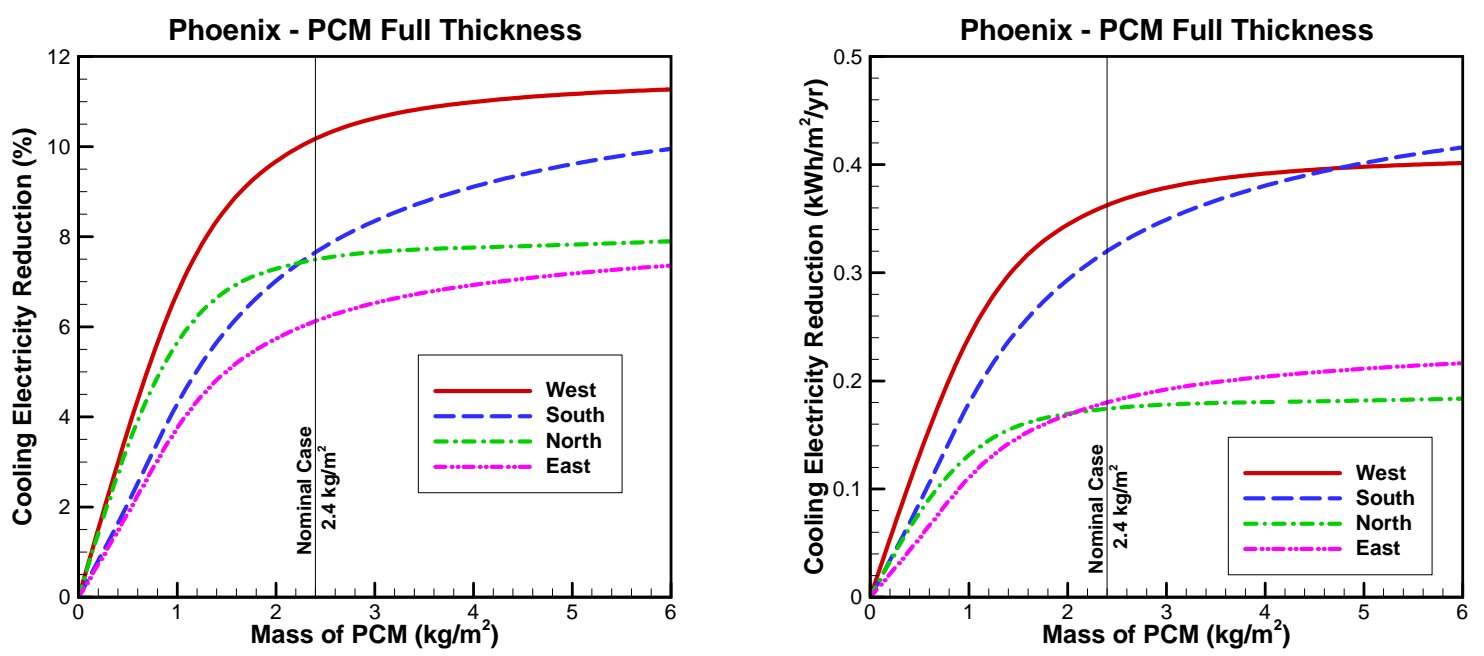

Figure 8 Impact of mass of PCM - PCM full thickness, $27^{\circ} \mathrm{C}$ melt midpoint, $4^{\circ} \mathrm{C}$ melt range

\subsubsection{Utility Rate Structures}

Phoenix has several options for time-of-day electricity pricing which have the potential to provide electricity cost savings greater than would be indicated by the reduction in electricity use produced by the use of PCM. Appendix B provides standard and time-of-day residential electricity rate plans available at the time of this study. The standard rate plan for summer does not use a fixed rate, but rather has a stepped structure where the incremental rate increses when usage levels exceed limits for 
the month. Therefore two differnet "standard" rates are considered: $0.16281 \$ / \mathrm{kWh}$ (total monthly usage less than $3000 \mathrm{kWh}$ ) and $0.17358 \$ / \mathrm{kWh}$ (usage greater than $3000 \mathrm{kWh}$.) Figure 9 presents the annual cooling cost per square meter of wall area for a wall with PCM and time of day electricity pricing (in purple). This is compared to three pricing options for walls without PCM, two different standard rates and the same time of day rate plan as was used for the PCM. The PCM system is well-suited to the time of day price structure, such that the electricity cost savings can be much greater than the electricity savings ( $\sim 30 \%$ cost vs. $\sim 8 \%$ energy savings for the cases considered here).

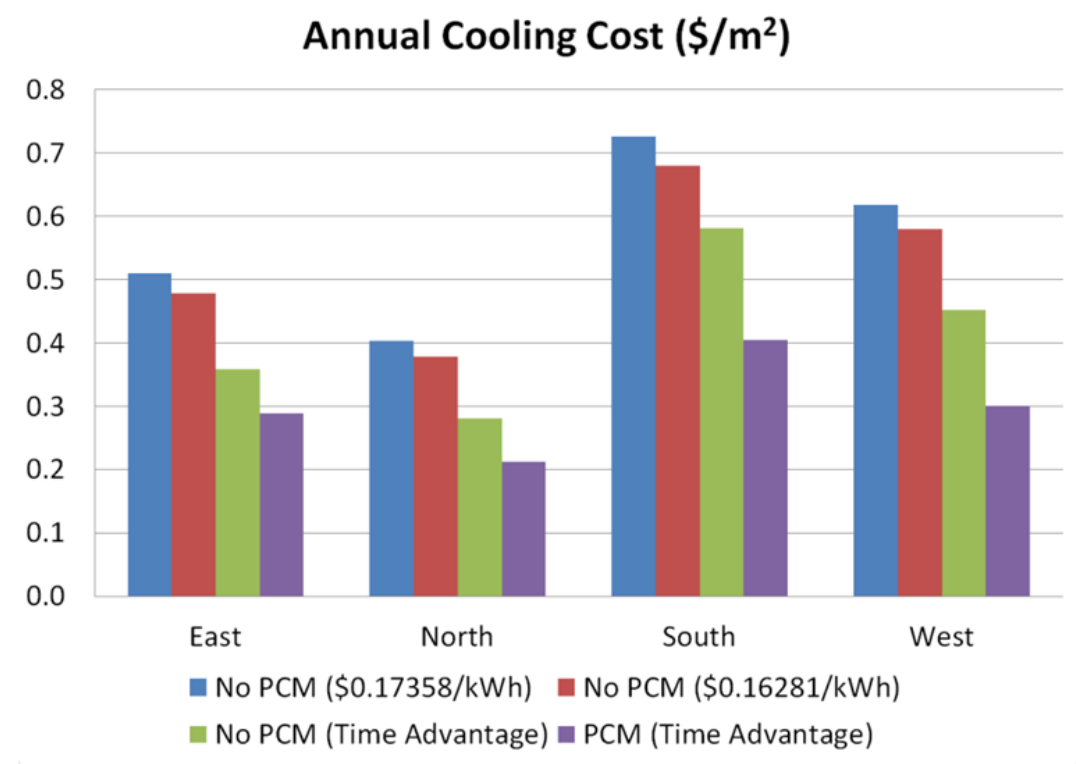

Figure 9 Annual cooling electricity cost - PCM full thickness, $2.4 \mathrm{~kg} / \mathrm{m}^{2}, 4^{\circ} \mathrm{C}$ melt range

\subsubsection{Optimal PCM}

The results presented up until now have all assumed that the PCM is uniformly distributed through the entire thickness of the cellulose and that the melt range is $4^{\circ} \mathrm{C}$. To determine the optimal benefit of PCM the impacts of the location of PCM in the wall and the melt curve need to be considered. To do this the HEATING model was coupled with an optimization program to identify the melt curve (i.e., the combined selection of the midpoint and width of the melt range) that produces the greatest reduction in cooling electricity use for any given PCM location. This optimization was done for three scenarios based on the location of the PCM: (1) an inner layer of cellulose containing PCM and an outer layer of only cellulose, (2) an inner layer of only cellulose and an outer layer of cellulose containing PCM and (3) a layer of cellulose containing PCM sandwiched between two layers of only cellulose. The total amount of PCM in the wall is held constant at $2.4 \mathrm{~kg} / \mathrm{m}^{2}$. The width of the layer containing the PCM was varied for all three scenarios. Note that the three scenarios converge for the case where the width of that layer is equal to the width of the cavity.

Figure 10 shows results for the case where the PCM is progressively concentrated in thinner layers towards the inside surface of the wall. Greater reductions in cooling electricity use can be achieved by concentrating the PCM nearer the inside surface; but to achieve this improvement the melt temperatures must be altered. As the PCM is concentrated nearer the inside surface the optimal melt midpoint temperature approaches the cooling setpoint, and the optimal melt range decreases. This location, near the inside wall, produce the greatest reduction in cooling energy use for Phoenix. 
Figure 11 shows results for the case where the PCM is progressively concentrated in thinner layers towards the outside surface of the wall. As the PCM is concentrated toward the outside surface of the wall there is a dramatic drop-off in reduction in cooling electricity use. Also as the PCM is concentrated nearer the outer surface a much higher melt midpoint temperature is required for optimal performance, and this midpoint temperature is significantly different depending on wall orientation. Clearly, to reduce cooling electricity use in Phoenix, concentrating the PCM toward the outer surface is not a good option.

Figure 12 shows results for the case where the PCM is progressively concentrated in thinner layers in the middle of the cellulose. The potential cooling electricity use reduction is not significantly affected by the thickness of the layer containing the PCM.
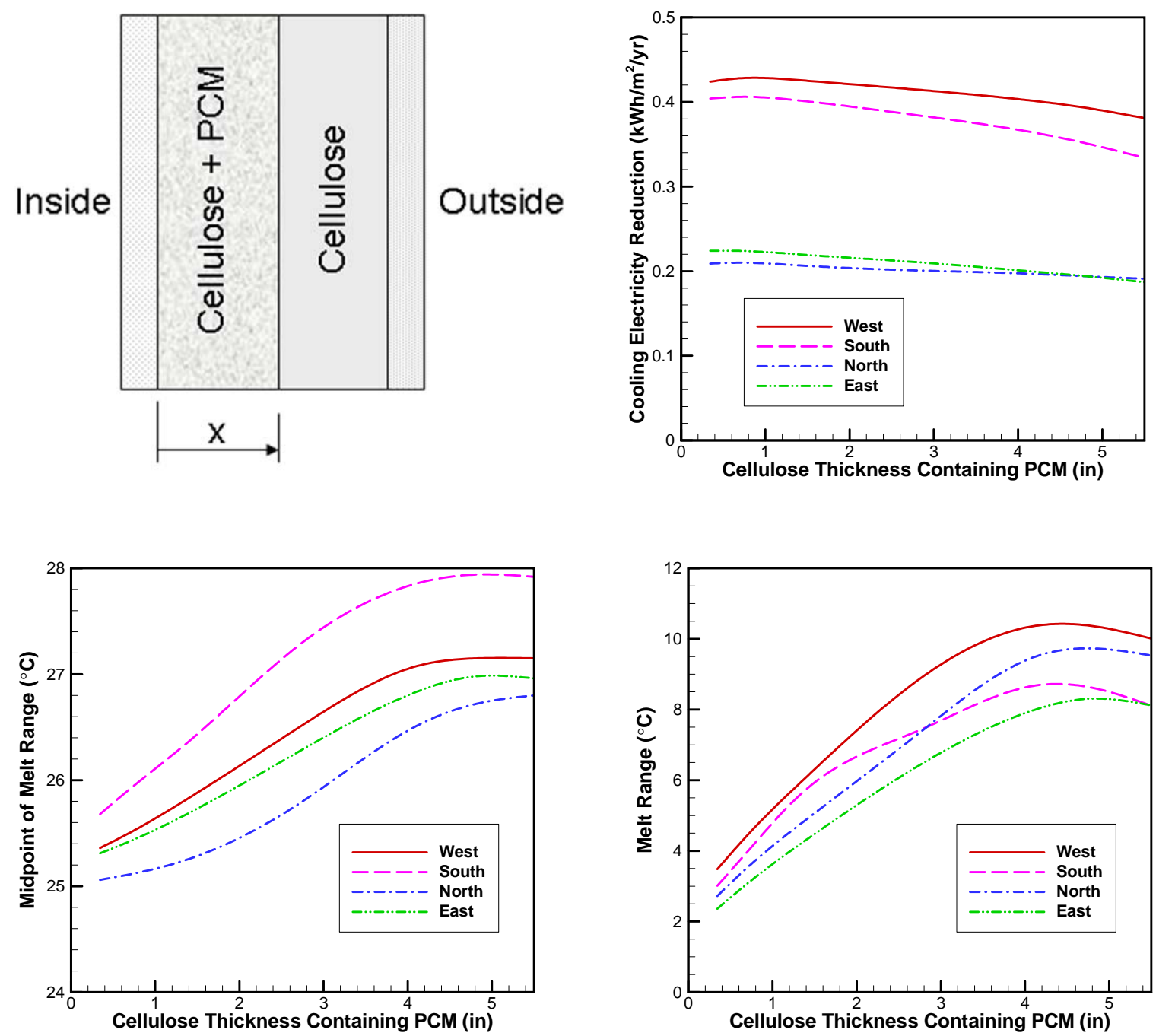

Figure 10 Optimal PCM properties, PCM concentrated toward inside, $2.4 \mathrm{~kg} / \mathrm{m}^{2}$ 

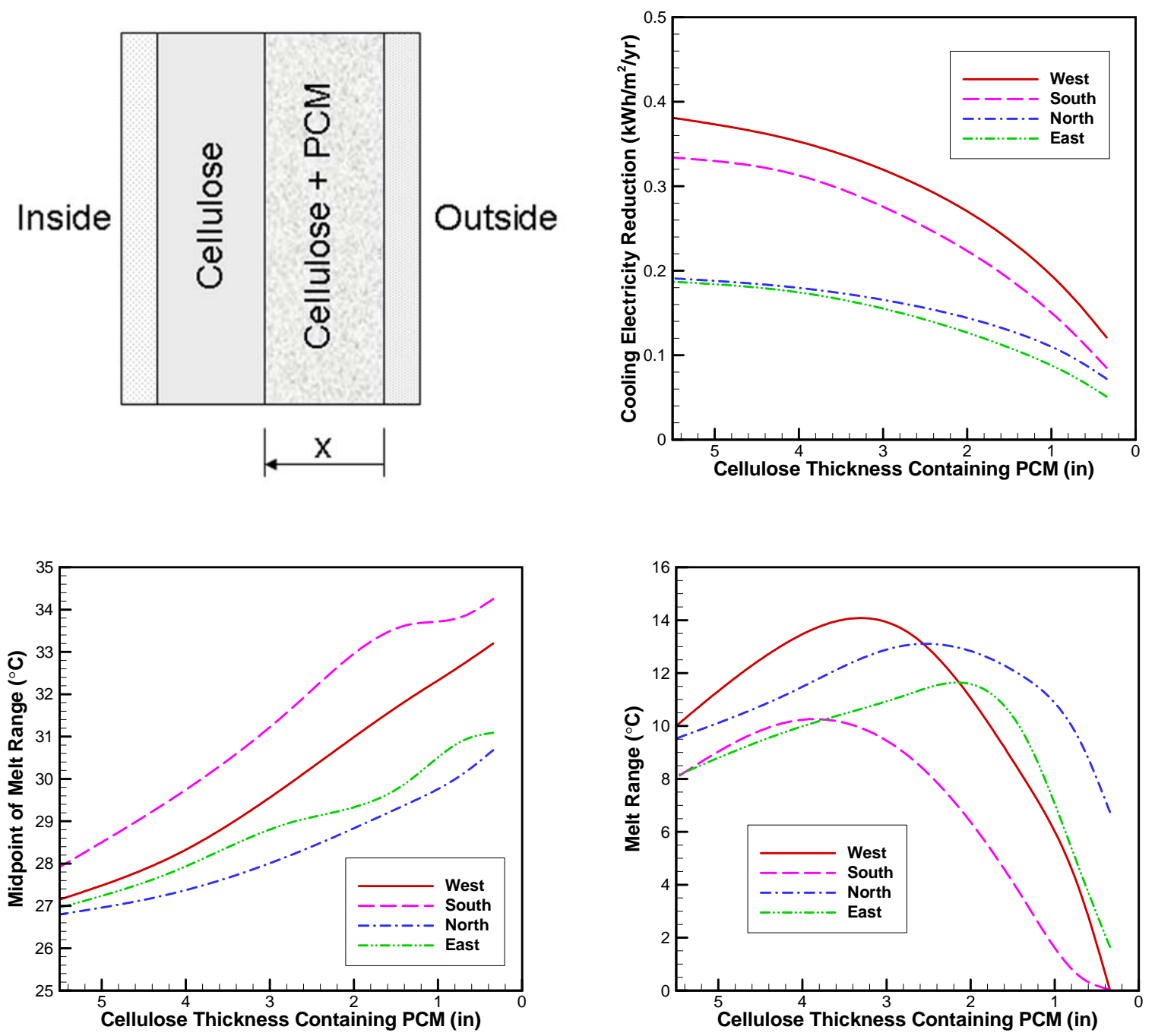

Figure 11 Optimal PCM properties, PCM concentrated toward outside, $2.4 \mathrm{~kg} / \mathrm{m}^{2}$ 

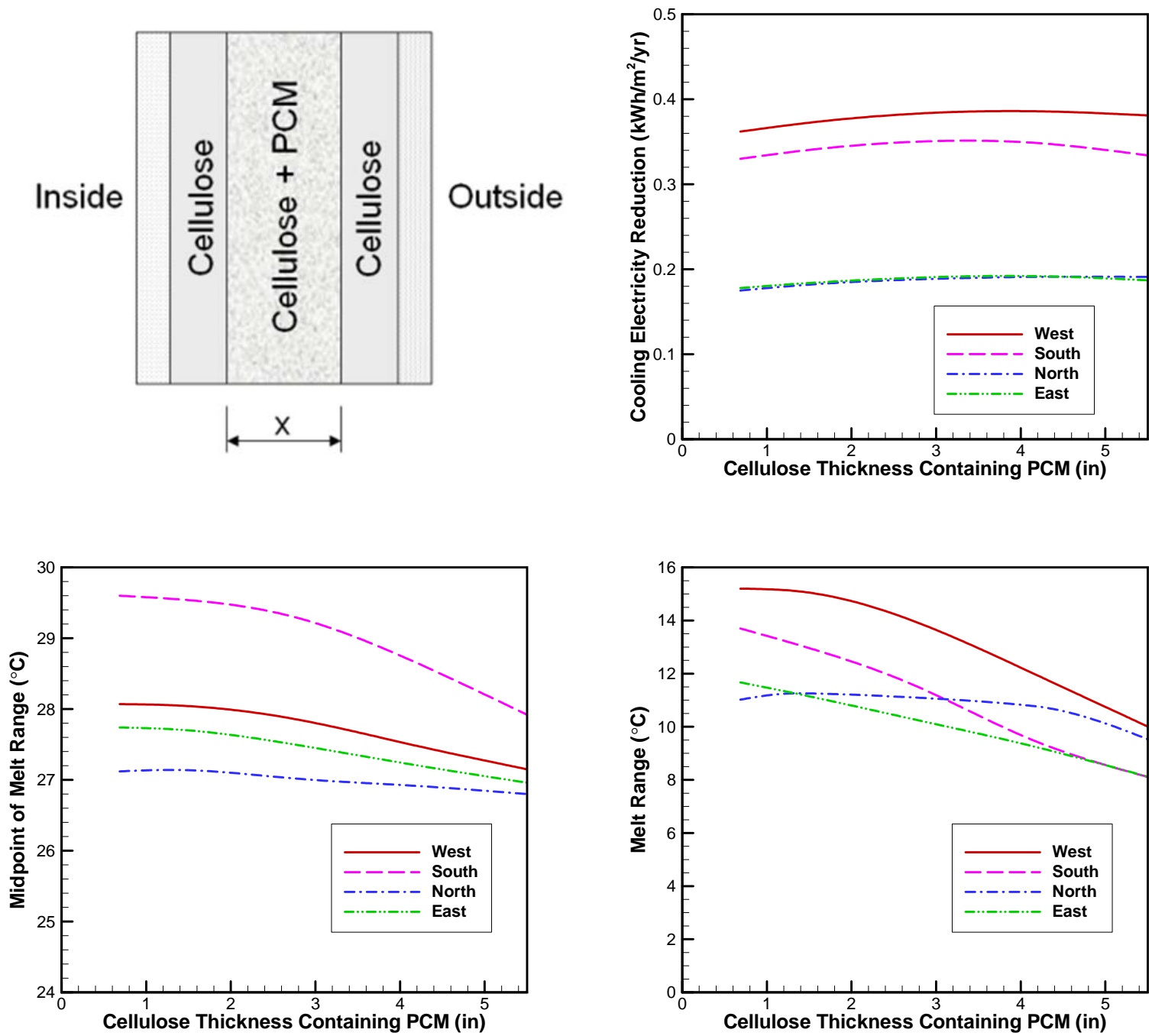

Figure 12 Optimal PCM properties, PCM concentrated in middle, $2.4 \mathrm{~kg} / \mathrm{m}^{2}$

\subsubsection{Melt Range}

Figure 5 indicates that the reduction in cooling electricity use achieved is fairly sensitive to the midpoint of the melt range - a deviation of a degree or two from the optimal value can dramatically decrease any benefit from the PCM. The sensitivity of the reduction in cooling electricity use to the melt range width is addressed in Figure 13. The plot on the left is for full thickness PCM for four wall orientations, and the plot on the right is for a west-facing wall with three different PCM locations. These plots indicate that the reduction in cooling electricity use is not very sensitive to the width of the melt range. So, even though Figures 10-12 show that the optimal melt range varies significantly depending on the thickness of the PCM layer, the overall variation in cooling electricity use is relatively small. This lack of sensitivity of cooling electricity use to the melt range midpoint and width is further illustrated in Figure 14 which shows energy use as a function of both melt midpoint and melt range. In this figure, the variation in energy use varies significantly from side to side as the midpoint temperature changes, but very little from top to bottom as the width of the melting range changes. 

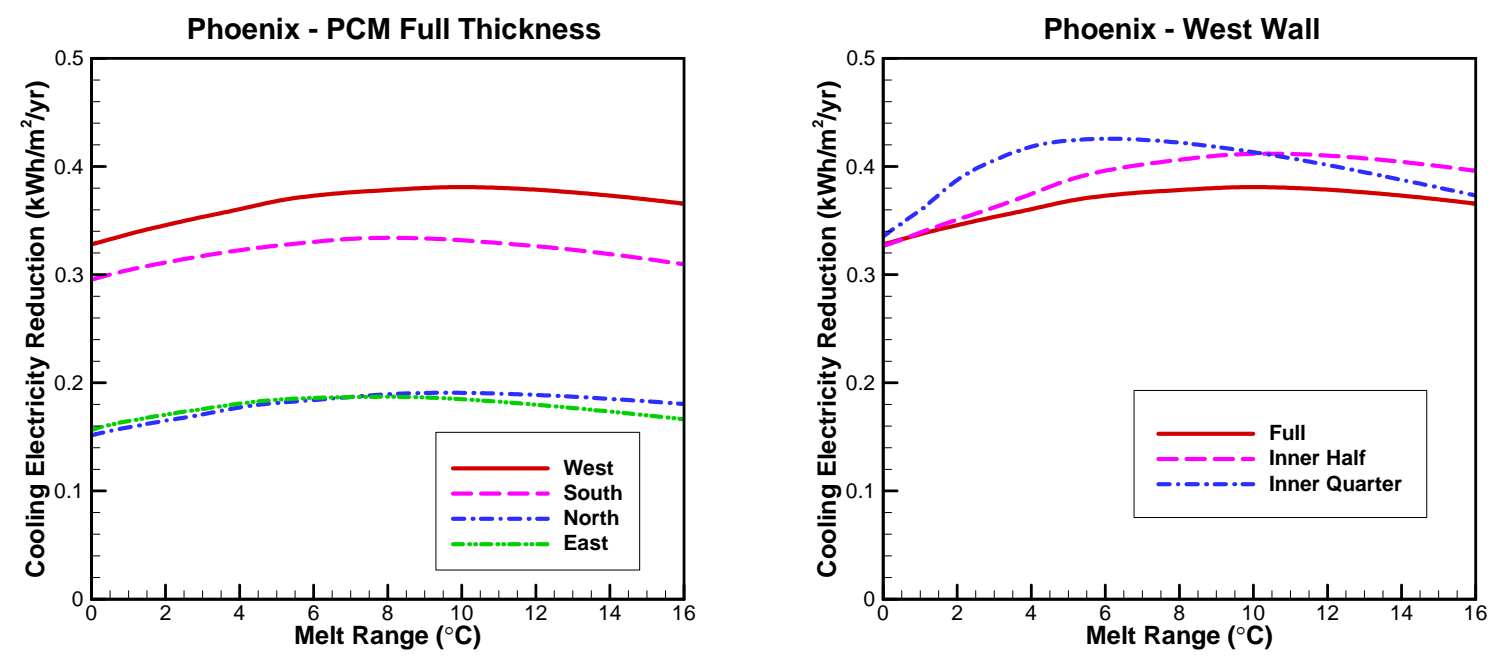

Figure 13 Cooling electricity reduction sensitivity to non-optimal PCM melt range - Optimal melt midpoints, $2.4 \mathrm{~kg} / \mathrm{m}^{2}$
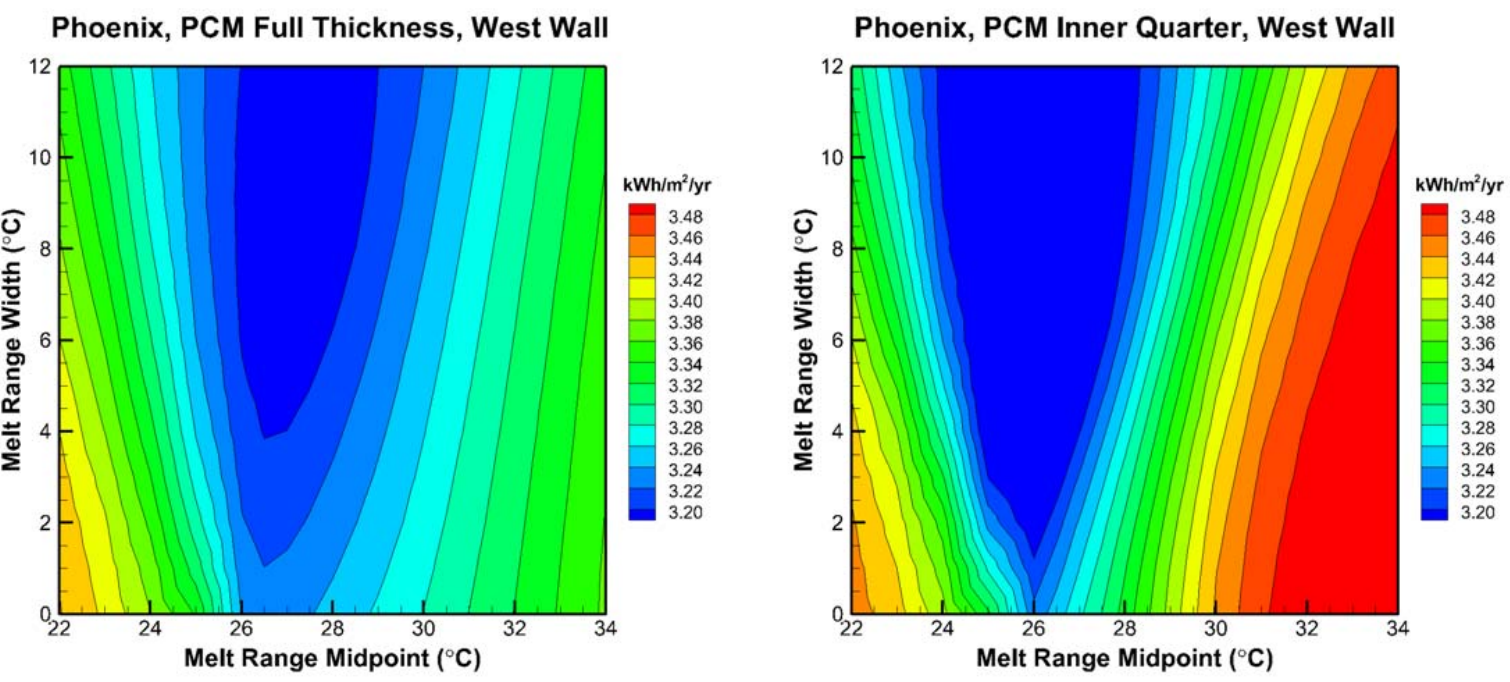

Figure 14 Cooling electricity use sensitivity to melt range midpoint and width $-2.4 \mathrm{~kg} / \mathrm{m}^{2}$

\subsubsection{Setpoint Temperature}

The setpoint temperature selection, with or without PCM in the wall, determines how many hours per year the building will need to be actively heated and cooled. For example, if the occupants prefer warmer temperatures, the number of hours of heating will increase and the number of hours of cooling will decrease. The impact of such changes will vary by climate, according to the local environmental temperature distribution relative to the selected setpoint temperature.

The optimal PCM melt midpoints described previously are for a specific set of assumptions. If the wall is shaded rather than in full sun, if the wall exterior surface solar absorptivity is different, or if other factors are varied, the optimal melt midpoint would likely be different. As the PCM is concentrated 
nearer to the inside surface, the optimal melt midpoint approaches the cooling setpoint temperature. So when the PCM is near the inside, the optimal melt midpoint is more predictable since it largely dependent on the cooling setpoint and is not heavily influenced by other factors. However, this characteristic is only as well defined as the setpoint temperature itself is defined.

The influence of variations in the setpoint temperature is therefore examined. For full thickness PCM, and using the optimal melting curve identified based on the assumed $25^{\circ} \mathrm{C}$ setpoint, changing the cooling setpoint a couple of degrees has very little impact on the cooling electricity savings, but as the PCM is concentrated in thinner layers near the inside, the cooling setpoint selection has a much more pronounced impact, as shown in Figure 15.

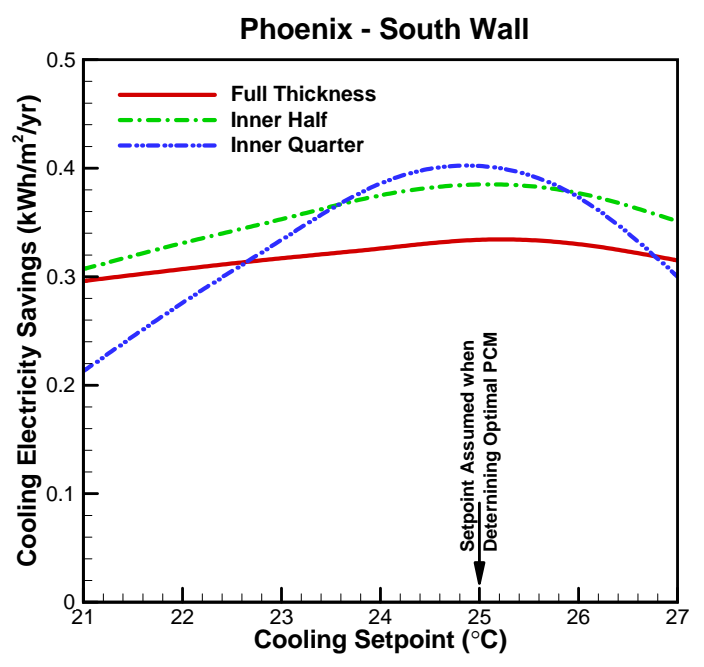

Figure 15 Sensitivity to altered cooling setpoint 


\subsubsection{Wall Framing and Thermal Bridging}

The results presented to this point have only looked at the performance of a wall without thermal bridging. The actual wall of interest has $2 \times 6$ studs placed 24 inches on center as shown previously in Figure 1. A two-dimensional model of the wall is utilized to determine how the presence of thermal bridges affects the performance of the PCM in reducing cooling electricity use. There is $2.4 \mathrm{~kg} / \mathrm{m}^{2}$ of PCM which is distributed through the full thickness of the cellulose. If the stud area and the clear-wall area behaved as independent parallel paths, then the reduction in cooling electricity use produced by the PCM would be expected to be less in the wall with bridges than in the wall without bridges. However, the temperature contours in the wall without PCM (top) and with PCM (bottom) at mid-afternoon in early July (see Figure 16) show that the presence of PCM in the cellulose has altered the temperature contours, and consequently the heat flow, through the stud. This new temperature profile shows that the temperature gradient, and thus the heat flow, near the interior wall has been reduced, which reduces the heat flow through the thermal bridge and into the interior space. The reduction in cooling electricity use, which is actually greater in the wall with bridges, is shown in Figures 17 and 18. Figure 17 shows how the influence of location in the wall, and Figure 18 shows the impact of wall orientation. A metal stud wall was also analyzed and showed results similar to those for the wood frame wall.

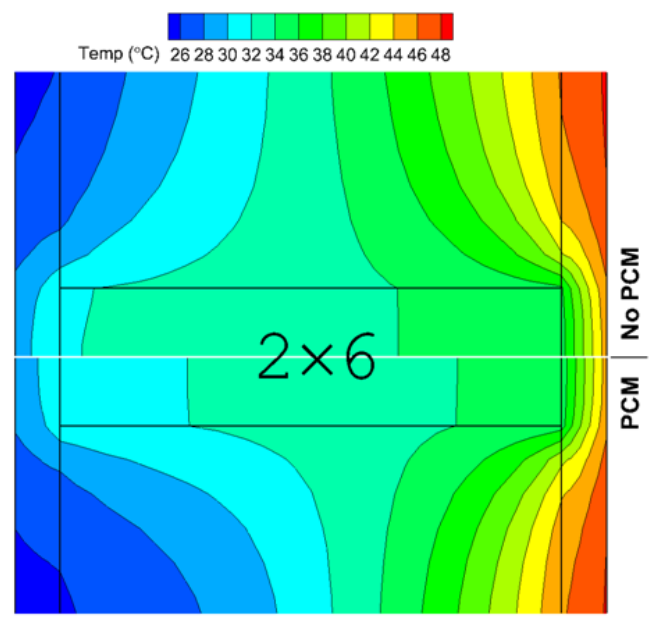

Figure 16 Temperature contours without PCM (top) and with PCM (bottom) - west wall, PCM full thickness, early July, mid-afternoon, indoor face on left 
Cooling Electricity Savings due to PCM

$\left(\mathrm{kWh} / \mathrm{m}^{2} / \mathrm{yr}\right)$

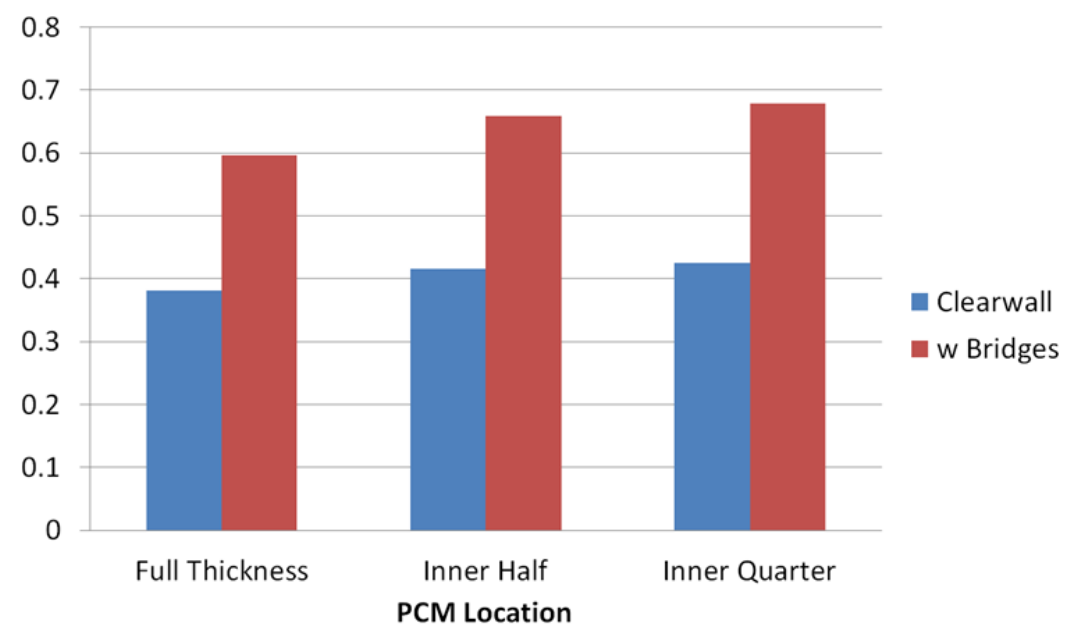

Figure 17 Electricity savings due to PCM with and without thermal bridging - optimal melt properties, $2.4 \mathrm{~kg} \mathrm{PCM} / \mathrm{m}^{2}$ wall surface area, West wall
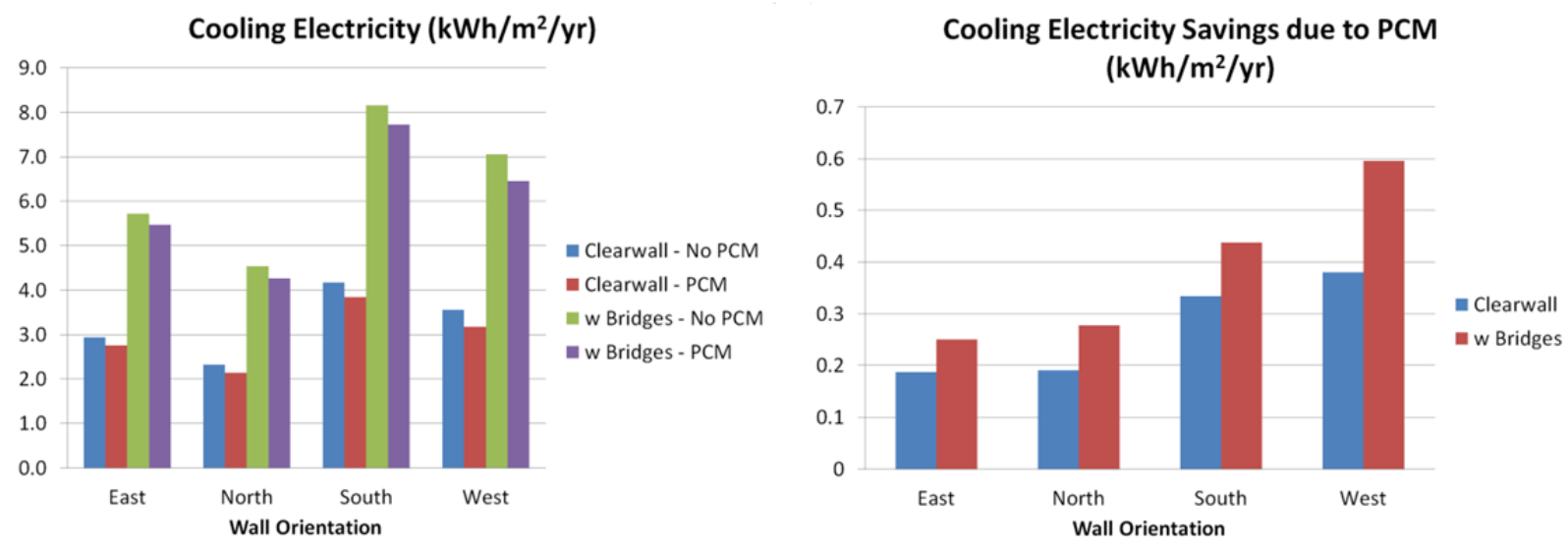

Figure 18 Electricity savings due to PCM with and without thermal bridging - PCM full thickness, optimal melt properties, $2.4 \mathrm{~kg} \mathrm{PCM} / \mathrm{m}^{2}$ wall surface area

\subsubsection{Commercially-available PCM}

The previous analyses reported here indicate that for a given location of the PCM in the wall, a specific midpoint and width of the melt range will produce the maximum benefit from the PCM. While there is some flexibility in formulating a PCM to obtain desired melt characteristics, it is not possible to exactly match the optimal characteristics. Figure 19 gives the melt characteristics of one particular commercially-available, micro-encapsulated PCM. Using this melt curve and the same analysis tools, the optimal placement of this PCM in a wall and the resulting performance were determined. 


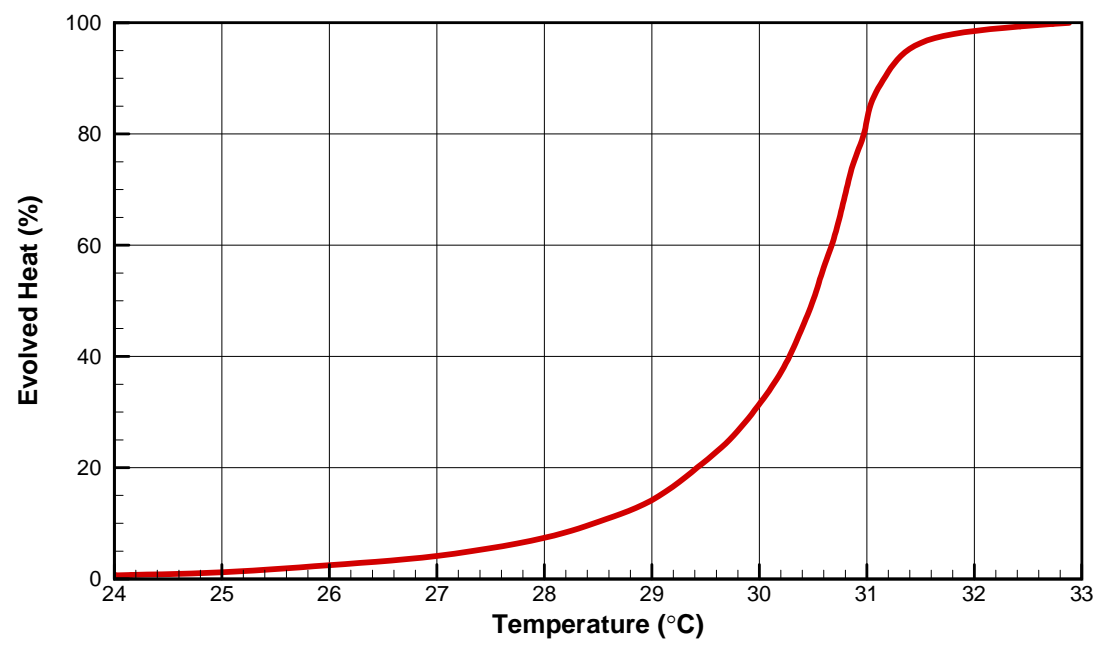

Figure 19 Melt curve

The results are shown in Figures 20 and 21. The greatest cooling electricity savings occur in south- or west-facing walls. The optimal location for this PCM within the wall is a layer of cellulose with PCM in the middle portion of the cellulose insulation for all four wall orientations, as shown in Figure 20. This location performs slightly better than having the PCM uniformly distributed through the entire cellulose thickness. However, from a practical standpoint, the incremental savings probably do not justify the added complexity of installing the insulation in three layers (cellulose, cellulose with PCM, cellulose.) Figure 21 compares the performance of the commercially-available PCM to a PCM with optimal melt characteristics. For full thickness PCM the commercially-available PCM performs 13-28\% worse than the optimal PCM depending on wall orientation.

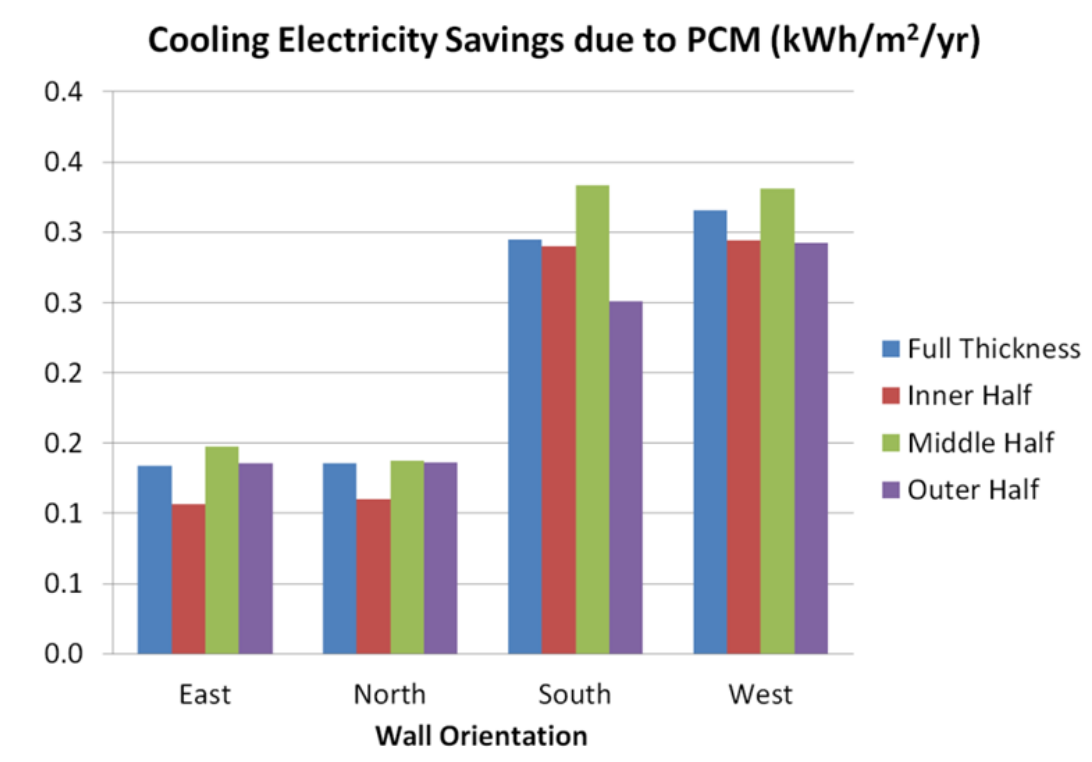

Figure 20 Cooling electricity savings with a commercially-available (non-optimal) PCM, $2.4 \mathrm{~kg} \mathrm{PCM} / \mathrm{m}^{2}$ wall surface area 


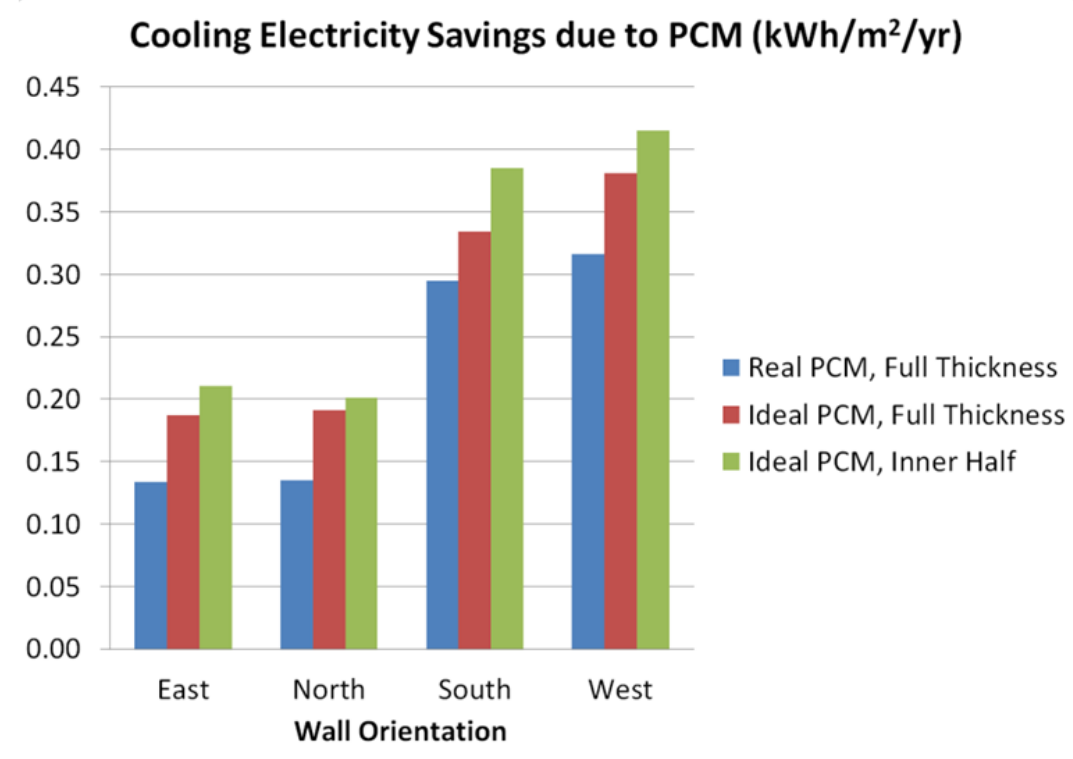

Figure 21 Cooling electricity savings with commercially-available PCM compared to optimal PCM, 2.4 $\mathrm{kg} \mathrm{PCM} / \mathrm{m}^{2}$ wall surface area

\subsubsection{Hysteresis}

In the previous section it was assumed that the commercial PCM examined does not exhibit hysteresis, but testing indicates that this commercial PCM can exhibit hysteresis. The melt and freeze curves are shown in Figure 22.

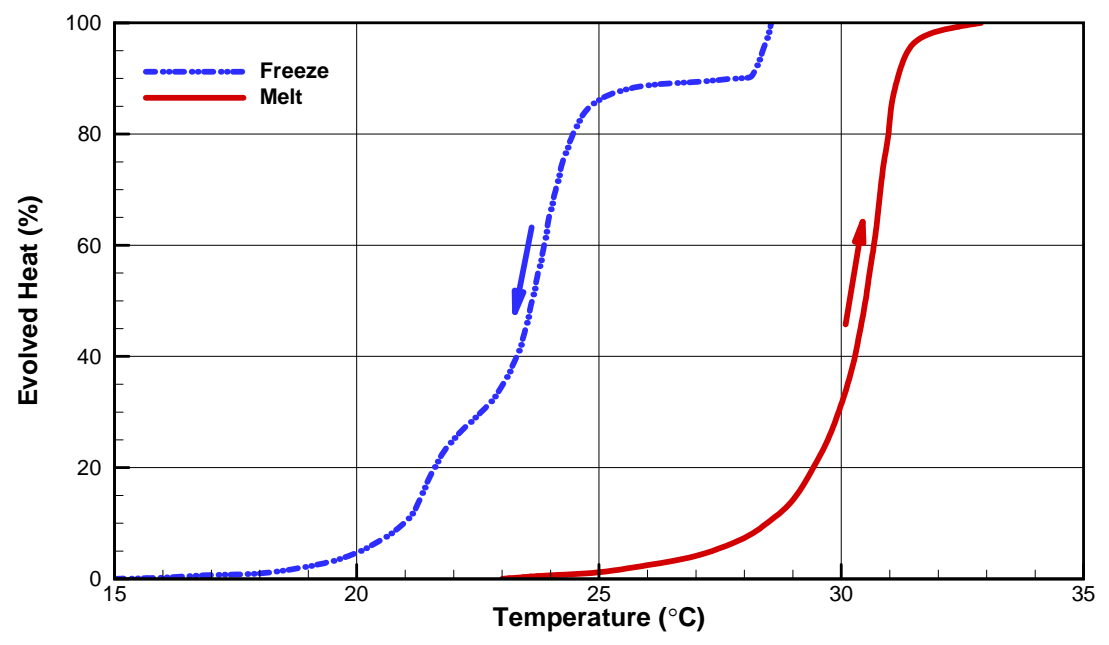

Figure 22 Melt and freeze curves

The HEATING code has been modified to model a PCM with separate melt and freeze curves. In this implementation any melt transient follows the melt curve, and any freeze transient follows the freeze curve. This means that a PCM that has undergone a partial melt which then experiences a drop in temperature will maintain the constant melt fraction until the temperature has dropped sufficiently to intersect the freeze curve. Only after the freeze curve is intersected can the melt fraction decrease. A 
similar scenario occurs for a partial freeze followed by an increase in temperature. The impact that a hysteresis like the one just described can have on cooling electricity savings is illustrated in Figure 23. The hysteresis reduced the effectiveness of the PCM in reducing cooling electricity use from $37 \%$ to $60 \%$ depending on the wall orientation.

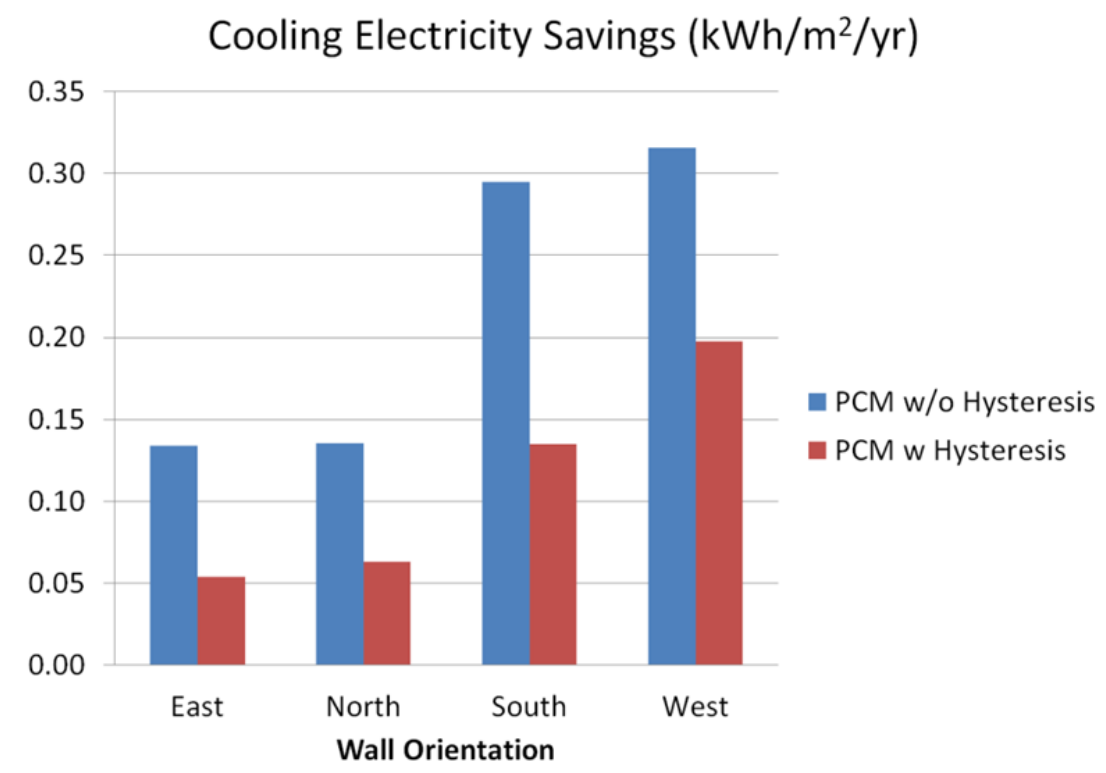

Figure 23 Impact of hysteresis on cooling electricity savings

However evidence suggests that this simple hysteresis model does not accurately represent the actual PCM behavior. Laboratory measurements show that when this particular PCM experiences a partial melt followed by a refreezing, the freezing process actually goes back down the melt curve rather than switching to the freeze curve. It appears that the PCM must experience a complete melt, and possibly even exceed the melt range upper bound, before the freezing process will follow the freeze curve rather than the melt curve. It is not clear what occurs when there is a partial freezing followed by remelting. The actual performance of the PCM in reducing cooling electricity use will fall somewhere between the two models presented. One conclusion that can be reached is that the phase change characteristics of a PCM must be known in order for any possible benefit to be estimated. Further investigation into the phase change behavior of the PCM is needed.

\subsection{Baltimore}

All of the calculations performed for Phoenix were repeated for Baltimore (with the exception of timeof-day pricing which was unique to Phoenix.) The results are given below.

\subsubsection{Phase Change Temperature and Load Reductions}

For a south-facing wall the percent reductions in various loads as compared to performance without PCM were calculated for the different midpoint melt temperatures. The results, shown in Figure 24, suggests that there is a potential for a high percent reduction in cooling loads in Baltimore, but very little opportunity for reductions in heating loads. So even for the milder cooling climate of Baltimore the load to target is still cooling electricity use. The fact that the reduction in cooling electricity use is only slightly 
greater than the reduction in annual cooling load, indicating that time shifting of cooling loads is not as effective a mechanism for cooling energy consumption reduction in Baltimore as it is in Phoenix.

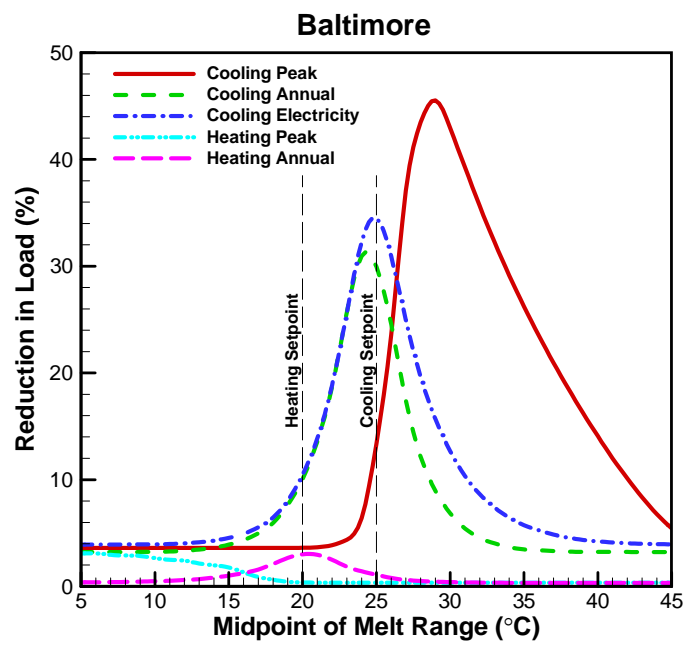

Figure 24 Impact of melt midpoint on heating/cooling loads - south wall, PCM full thickness, 2.4 $\mathrm{kg} / \mathrm{m}^{2}, 4^{\circ} \mathrm{C}$ melt range

\subsubsection{Wall Orientation}

Figures 25 and 26 illustrate that PCM is most effective in reducing cooling loads when placed in west and south facing walls, just as in Phoenix. The south wall has the lowest percentage reduction in cooling electricity use but the highest actual reduction, whereas the north wall has the highest percentage reduction but the lowest actual reduction.
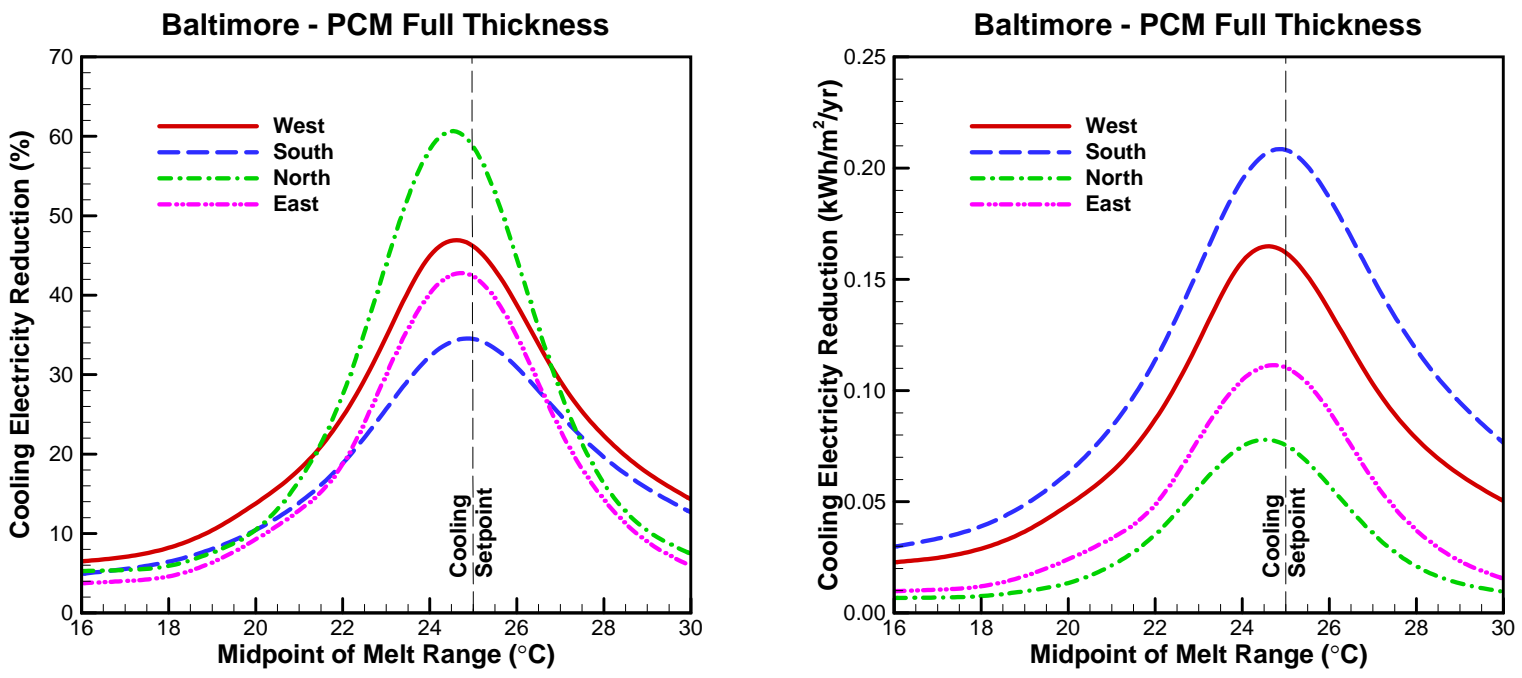

Figure 25 Impact of wall orientation - PCM full thickness, $2.4 \mathrm{~kg} / \mathrm{m}^{2}, 4^{\circ} \mathrm{C}$ melt range 

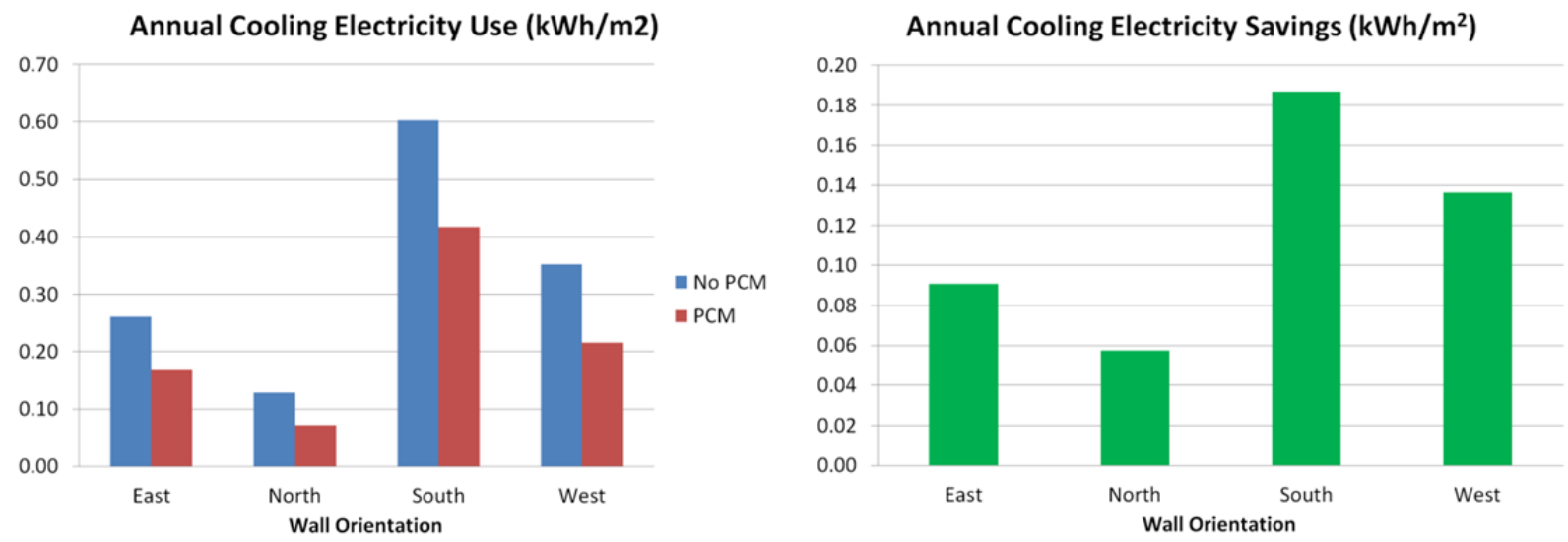

Figure 26 Annual cooling electricity use (L) and savings (R) - PCM full thickness, $2.4 \mathrm{~kg} / \mathrm{m}^{2}, 25^{\circ} \mathrm{C}$ melt midpoint, $4^{\circ} \mathrm{C}$ melt range

\subsubsection{Seasonal Performance}

Because of variations in ambient conditions throughout the year the ability of the PCM to reduce the cooling electricity also exhibits a seasonal dependence. To illustrate this seasonal variation a southfacing wall is examined. The midpoint of the melt range is set to $25^{\circ} \mathrm{C}$ since that optimizes the effectiveness of the PCM (see Figure 25.) Figure 27 shows the impact that PCM has on the cooling electricity use by month in percent (left) and in $\mathrm{kWh} / \mathrm{m}^{2}$ (right). Note that there is no cooling load due to conduction through the wall for January through March and October through December.
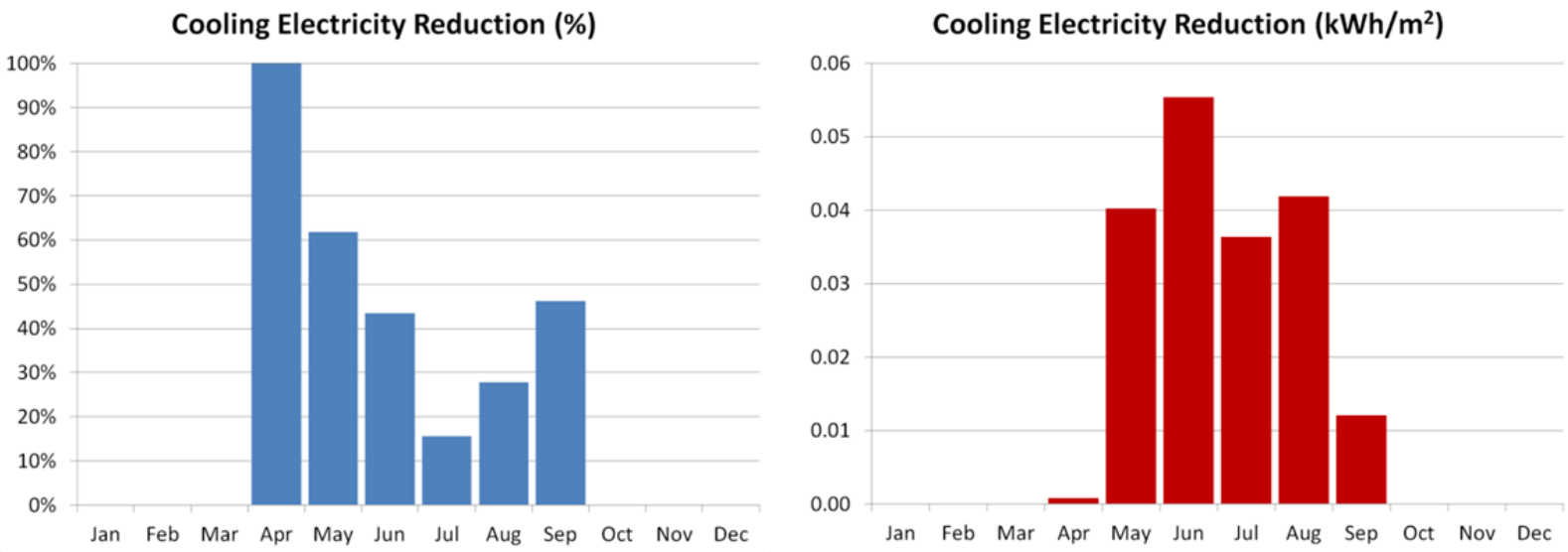

Figure 27 Cooling electricity reduction due to PCM - PCM full thickness, west wall, $25^{\circ} \mathrm{C}$ melt midpoint, $4^{\circ} \mathrm{C}$ melt range

\subsubsection{PCM Amount}

The relationship between savings and the amount of PCM placed within the wall is shown in Fig. 28. The selection of an economically optimal amount of PCM is less clear here than it was for Phoenix for the 
south wall, but the west wall shows a more distinct change in slope, indicating that an amount less than $1 \mathrm{~kg} / \mathrm{m}^{2}$ may be appropriate for that exposure.
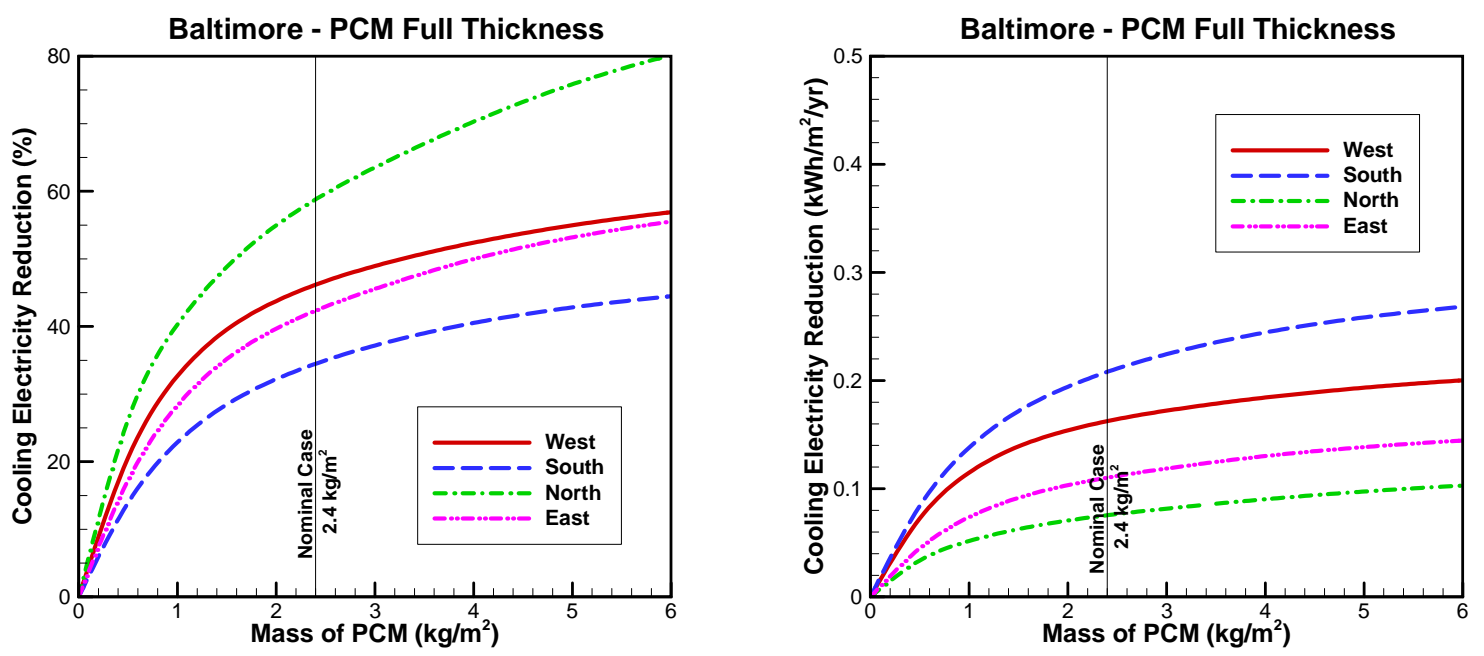

Figure 28 Impact of mass of PCM - PCM full thickness, $2.4 \mathrm{~kg} / \mathrm{m}^{2}, 25^{\circ} \mathrm{C}$ melt midpoint, $4^{\circ} \mathrm{C}$ melt mange

\subsubsection{Optimal PCM}

Figures 29, 30, and 31 show results for the three options for concentrating the PCM: (1) an inner layer of cellulose containing PCM and an outer layer of only cellulose, (2) an inner layer of only cellulose and an outer layer of cellulose containing PCM and (3) a layer of cellulose containing PCM sandwiched between two layers of only cellulose. Once again the total amount of PCM in the wall is held constant at $2.4 \mathrm{~kg} / \mathrm{m}^{2}$. For all three scenarios the optimum midpoint of the melt range is the cooling setpoint temperature. The optimal melt range is near zero (isothermal melt) for all scenarios except for the case where $\mathrm{PCM}$ is concentrated near the inside. Even for this case the optimal melt range only reaches $1^{\circ} \mathrm{C}$ on the south wall. However, as is shown later, the savings are not reduced by very much for wider melt ranges.

As was the case for Phoenix, concentrating the PCM toward the outside drastically reduces any benefit and concentrating toward the inside produces only slightly greater benefit than PCM uniformly distributed through the cellulose layer. Concentrating the PCM in the middle of the cellulose layer behaves essentially the same as having the PCM uniformly distributed through the entire cellulose thickness. Similar to the results for Phoenix, the savings are relatively insensitive to the width of the cellulose region for the inner and sandwich layer PCM placement options. 

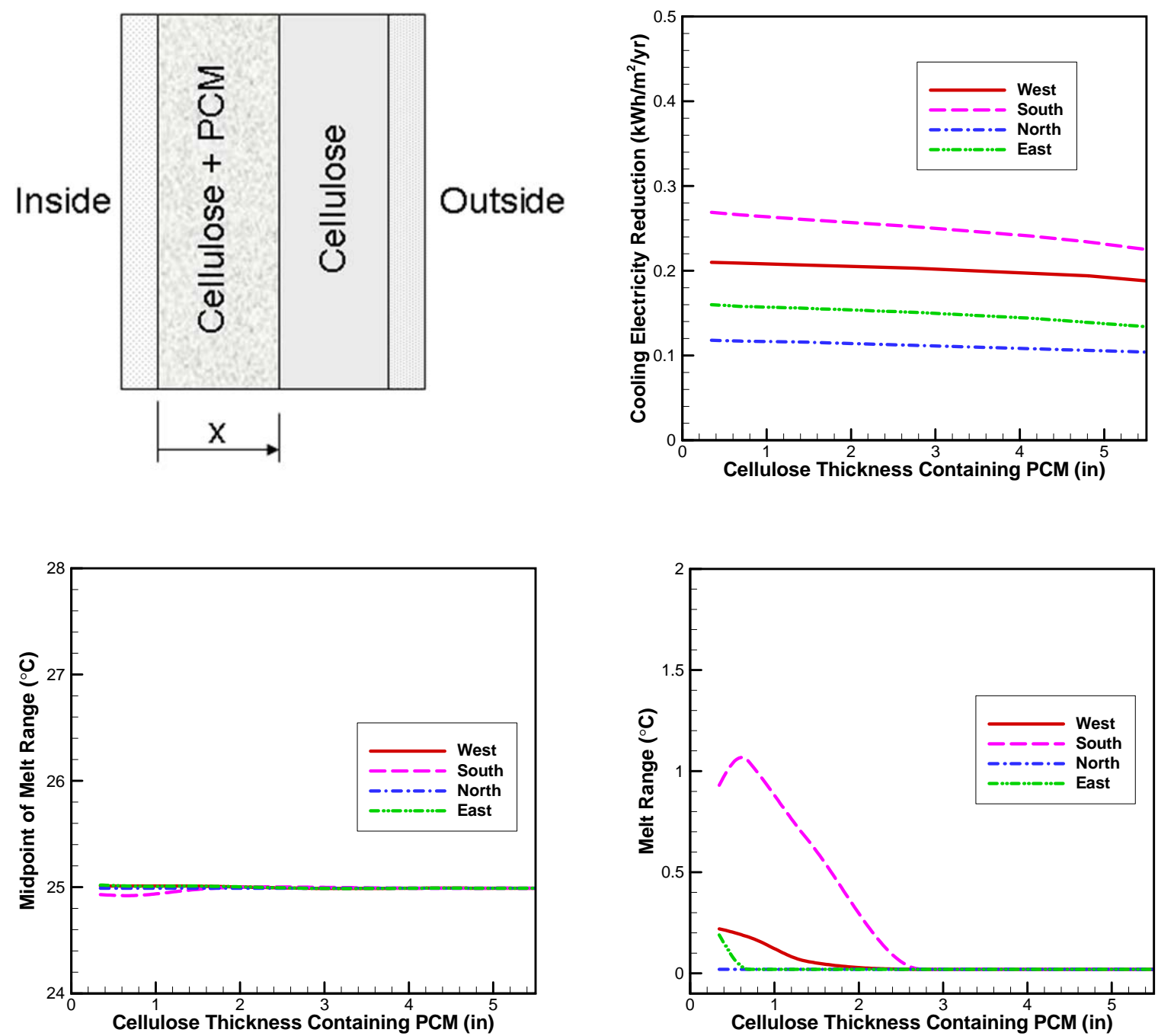

Figure 29 Optimal PCM properties, PCM concentrated toward inside, $2.4 \mathrm{~kg} / \mathrm{m}^{2}$ 

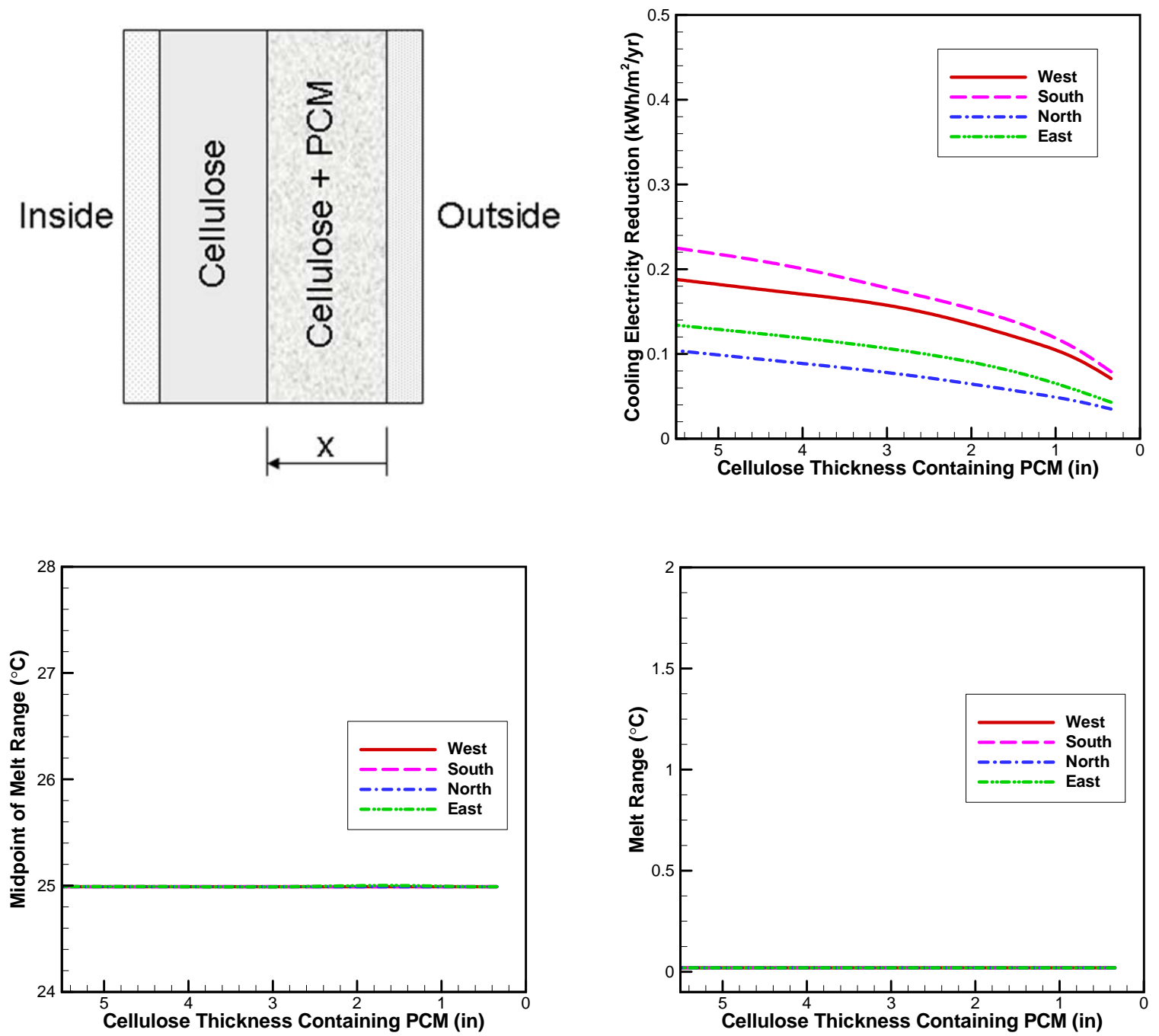

Figure 30 Optimal PCM properties, PCM concentrated toward outside, $2.4 \mathrm{~kg} / \mathrm{m}^{2}$ 

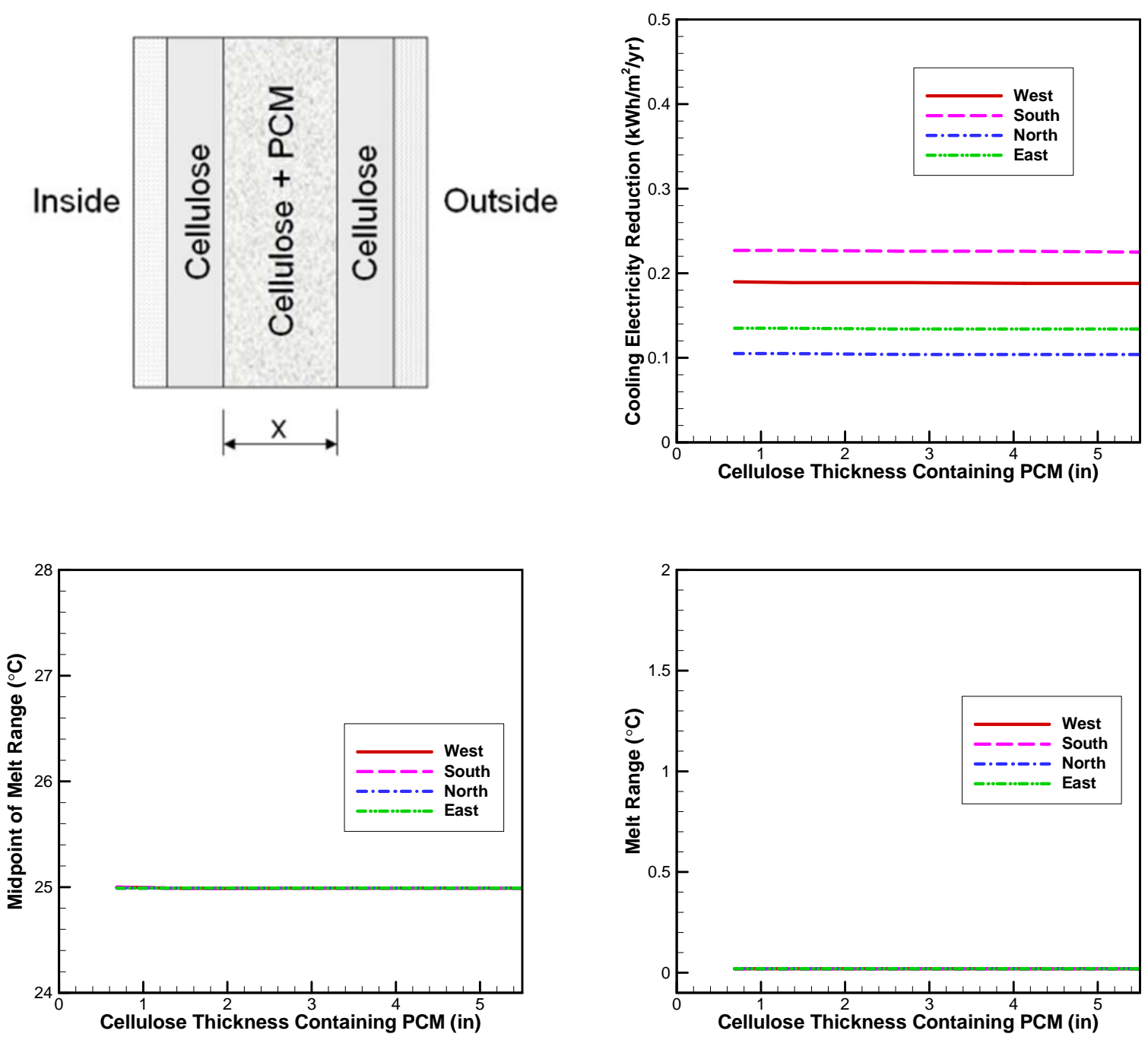

Figure 31 Optimal PCM properties, PCM concentrated in middle, $2.4 \mathrm{~kg} / \mathrm{m}^{2}$ 


\subsubsection{Melt Range}

Figure 25 indicates that the reduction in cooling electricity use achieved is fairly sensitive to the midpoint of the melt range - a deviation of a degree or two from the optimal value can dramatically decrease any benefit from the PCM. Figures 29-31 showed that the optimal melt range for almost every location was close to zero, that is, close to the behavior of an ideal PCM, not a real PCM. However, the sensitivity of the reduction in cooling electricity use to the melt range, shown in Figure 32, indicates that significant savings are still possible at melt ranges in the 2 to $4^{\circ} \mathrm{C}$ ballpark. The plot on the left is for full thickness PCM for four wall orientations, and the plot on the right is for a west-facing wall with three different PCM locations. This dependence of cooling electricity use on the melt range midpoint and width is further illustrated in Figure 33. Just as for Phoenix, the variation from side to side, that is, for variations in midpoint temperature, are much greater than the top to bottom variations in melt range width.
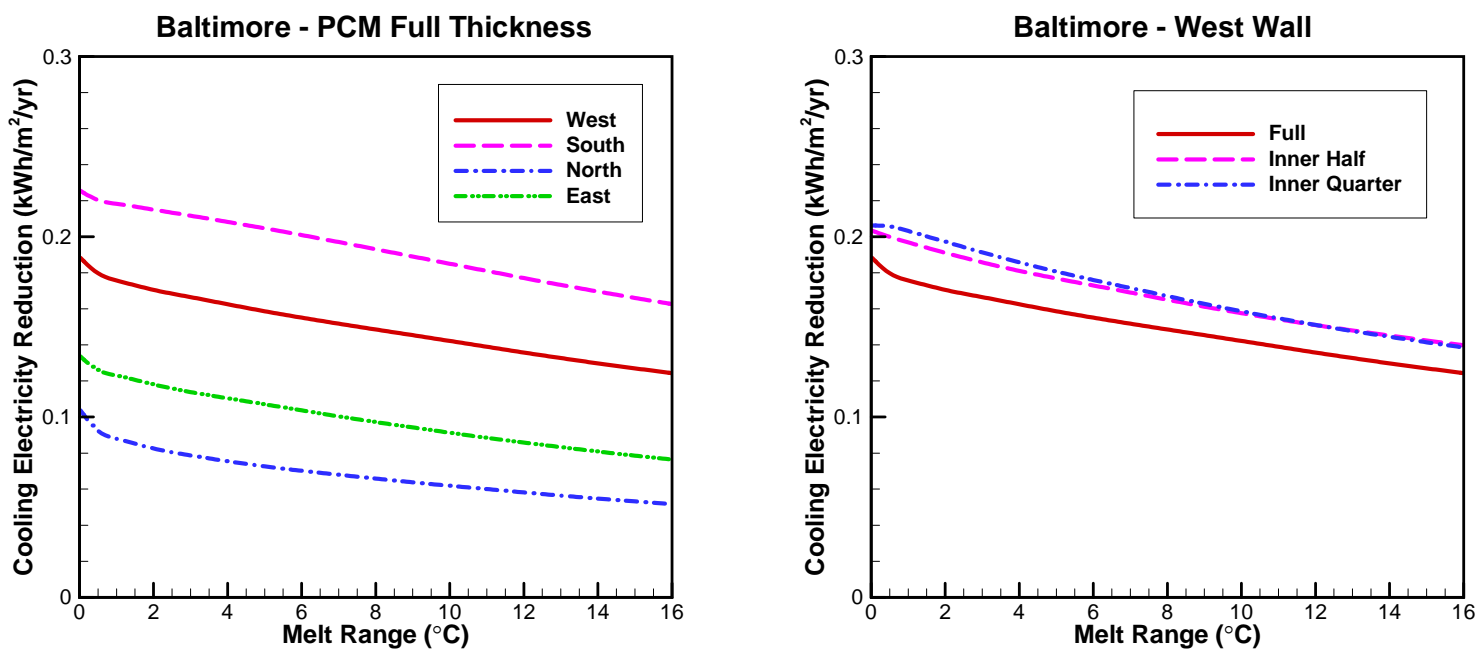

Figure 32 Cooling electricity reduction sensitivity to non-optimal PCM melt range - optimal melt midpoints, $2.4 \mathrm{~kg} / \mathrm{m}^{2}$

Baltimore, PCM Full Thickness, West Wall

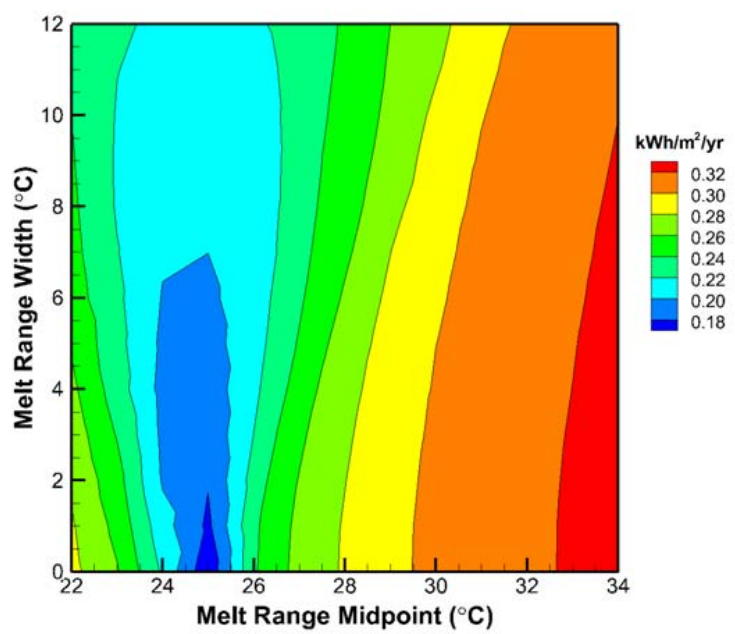

Baltimore, PCM Inner Quarter, West Wall

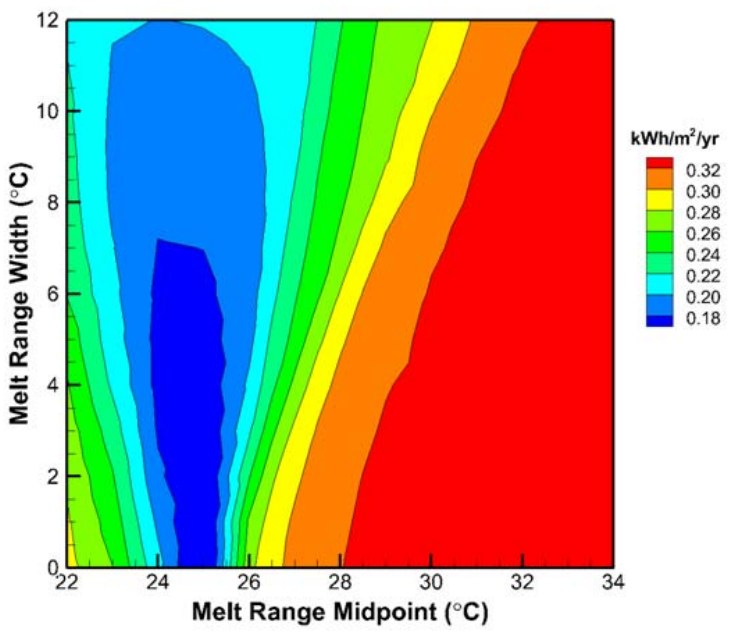

Figure 33 Cooling electricity use sensitivity to melt range midpoint and width $-2.4 \mathrm{~kg} / \mathrm{m}^{2}$ 


\subsubsection{Setpoint Temperature}

The influence of variations in the setpoint temperature is shown in Figure 34. The savings in Baltimore are about five times more sensitive to changes in the setpoint, even for the full thickness application, than they were in Phoenix. However, similar to Phoenix, the full thickness application is less sensitive to changes in the setpoint than cases with the PCM concentrated nearer the interior surface.

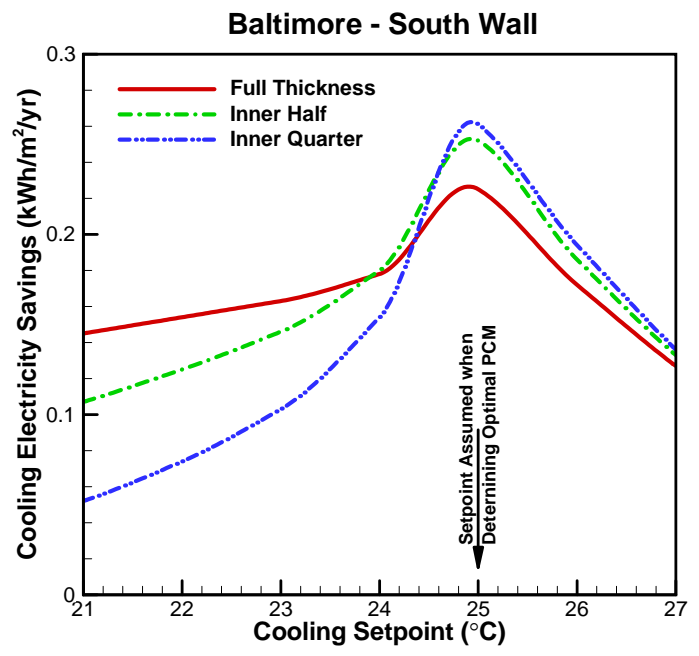

Figure 34 Sensitivity to altered cooling setpoint

\subsubsection{Wall Framing and Thermal Bridging}

Just as in Phoenix, the reduction in cooling electricity use is greater in the wall with bridges than in a clear wall section, as illustrated in Figure 35. Again, the presence of PCM in the cellulose has altered the temperature contours, and consequently the heat flow, through the stud, reducing the impact of the thermal bridge.
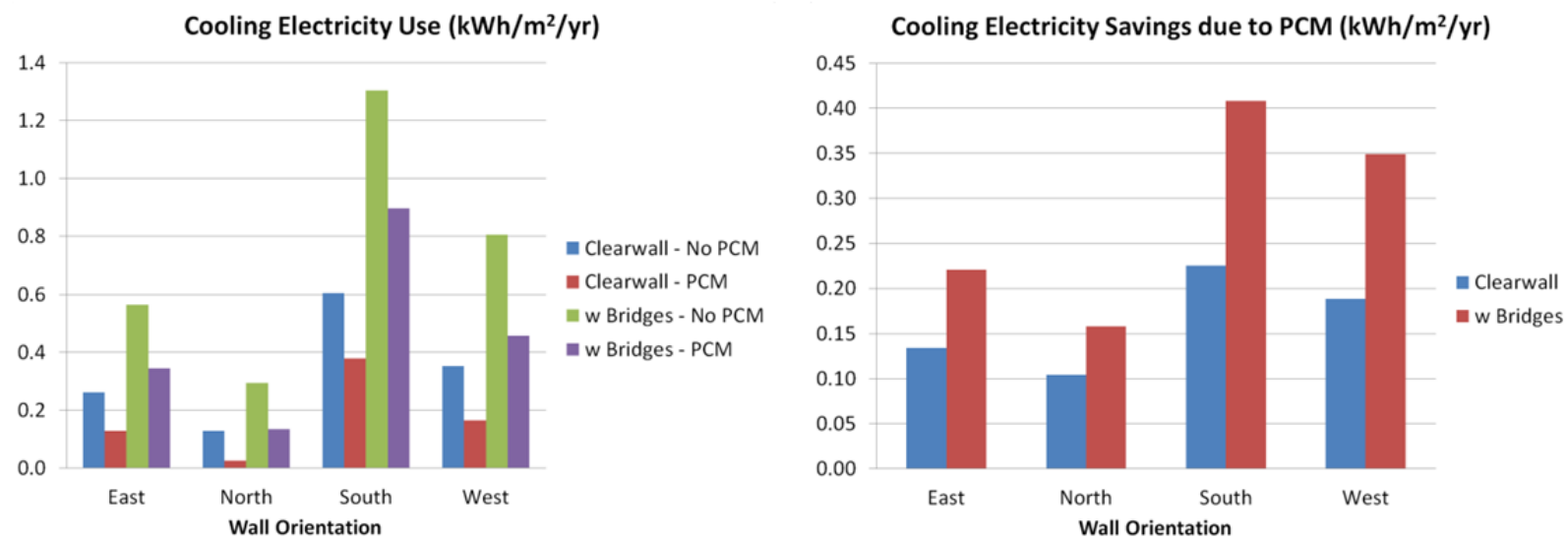

Figure 35 Electricity savings due to PCM with and without Thermal Bridging - Baltimore, PCM full thickness, optimal Melt Properties, $2.4 \mathrm{~kg} / \mathrm{m}^{2}$ wall surface area 


\subsubsection{Commercially-Available PCM}

Using the melt characteristics for one particular commercially available PCM, shown in Figure 19, the optimal placement of this PCM in a wall and the resulting performance were determined. Although the optimal melt temperature and range, combined with a location near the inside surface of the wall produced savings near $0.2 \mathrm{kWh} / \mathrm{m}^{2} /$ year, this particular PCM only produces savings of about half that amount, as shown in Fig. 36. This demonstrates the need to select a PCM with the optimal properties in mind for each location.

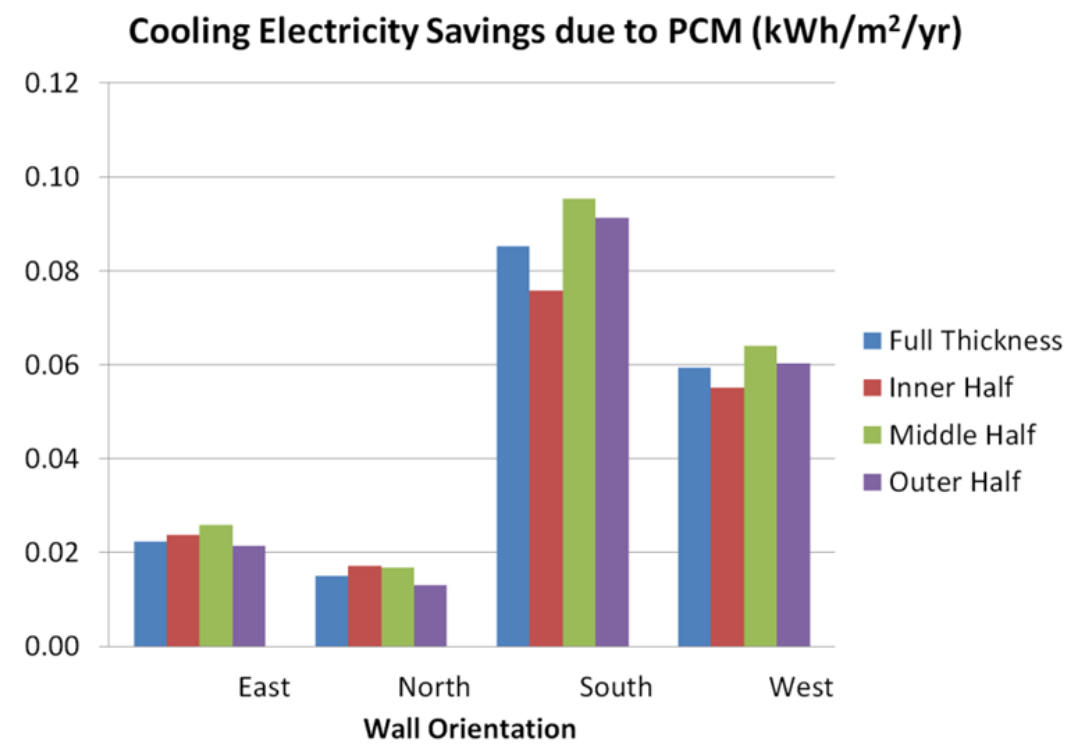

Figure 36 Cooling electricity savings with a commercially-available (non-optimal) PCM

\subsubsection{Hysteresis}

Figure 37 indicates that the presence of hysteresis in the PCM has only a small impact on cooling energy use in Baltimore. 


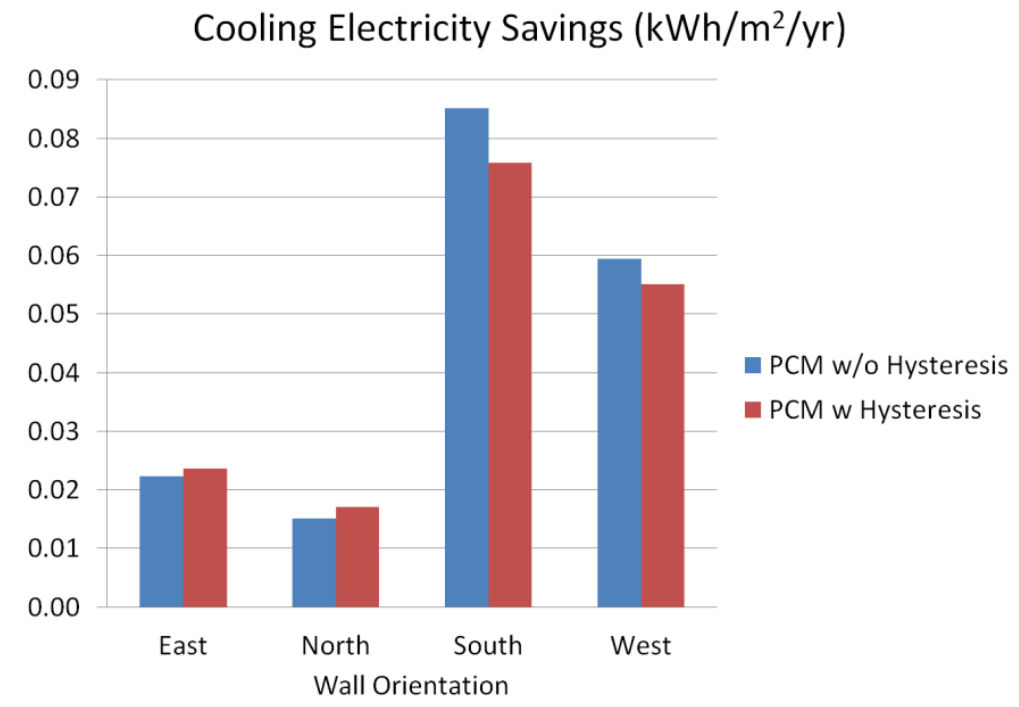

Figure 37 Impact of hysteresis on cooling electricity savings

\section{Observations and Conclusions}

The broader project includes three elements, (1) this parametric evaluation to define the maximum technical potential given optimal PCM properties in one type of wall application in two climates, (2) improving and benchmarking whole house model tools for use in evaluating PCM applications and (3) a consideration of the costs of PCM systems, now and when a full-scale industry model is in place.

This report describes the parametric evaluation of potential applications of a PCM-cellulose mixture installed within a wall cavity for two particular locations. One location, Phoenix, has very hot summers and a very dry climate. The other location, Baltimore, has more moderate temperature swings, but a greater latent load. In each location, realistic exterior conditions were applied to consider solar gains, night-time radiation, and convection. Realistic interior conditions were used, allowing the interior temperature to float between the winter and summer setpoints. This temperature float is important, because a fixed temperature assumption can lead to artificial savings estimates that would not be realized during spring and fall when the heating and cooling systems are often not needed.

Some results were similar for both locations.

- The addition of PCM to a well-insulated wall appears to have a minor impact on the overall cooling load of the building. However, PCM in building walls can reduce the amount of electricity needed to meet the annual cooling needs. Any cost benefit analysis should include savings for time-of-day rates where available. For example, in Phoenix, the system can save about $8 \%$ of the wall-related cooling electricity use, but about $30 \%$ of the wall-related cooling electricity cost when time of day rates are available.

- It is more cost effective to install the PCM system in walls facing south or west rather than east or north.

- $\quad$ PCM produces greater reductions in cooling electricity use in walls with thermal bridges than in idealized walls without bridges. (Phoenix: $62 \%$ Increased savings west wall, $30 \%$ increased savings south wall)(Baltimore: $80 \%$ south, $84 \%$ west) 
- The PCM wall system is effective at shifting peak loads and should be considered as a tool for utility demand reduction.

- The most effective location for the PCM-cellulose layer is throughout the full thickness of the wall cavity. Concentrating the PCM near the inner surface of the wall reduces cooling electricity use slightly as compared to PCM uniformly distributed through the entire thickness of the wall cavity when the phase change characteristics are optimized for each location and for a specific temperature set point. However, the performance of PCM placed closer to the interior is more sensitive to any variation in the indoor temperature setpoint. Since the setpoint is selected at different values by different occupants, the full thickness location is a more conservative choice. There is also added complexity and cost associated with with the installation of a layer of insulation/PCM and a then second layer of insulation only.

- Concentrating the PCM nearer the outer surface of the wall is not an effective strategy to reduce cooling electricity use in either climate studied. The benefit is dramatically less than same amount of PCM uniformly distributed throughout the entire thickness of the cellulose.

- The point of diminishing returns for the amount of PCM within the wall will vary with the PCM properties, application type, and climate. In one case examined, about 50\% of the PCM assumed here provided about $75 \%$ of the savings. Examining this issue will be important in any cost benefit analysis.

- Altering the cooling setpoint from the value assumed in PCM selection can significantly reduce the effectiveness of the PCM. Interestingly, although raising the cooling setpoint above the design value may decrease cooling electricity use, it actually reduces the impact of the PCM.

- The midpoint of the melt range for a PCM must be chosen to target the specific load of interest, that is, an installation with a goal of reducing the peak demand will have a higher melting midpoint than an installation with a goal of reducing annual electricity use.

Other results showed a greater variability between the two climates.

\begin{tabular}{|l|l|}
\hline \multicolumn{1}{|c|}{ Phoenix } & \multicolumn{1}{|c|}{ Baltimore } \\
\hline $\begin{array}{l}\text { The optimal midpoint temperature is dependent on } \\
\text { wall orientation, location of PCM in the wall, and } \\
\text { cooling setpoint. For full thickness applications: West } \\
\text { and South: about } 2^{\circ} \mathrm{C} \text { above setpoint; North and East: } \\
\text { about } 1^{\circ} \mathrm{C} \text { above setpoint }\end{array}$ & $\begin{array}{l}\text { The optimal midpoint temperature is always the cooling } \\
\text { setpoint temperature. }\end{array}$ \\
\hline $\begin{array}{l}\text { Cooling electricity savings increase slightly as melt } \\
\text { range increases ( } 13 \% \text { improvement as melt range goes } \\
\text { from } 0 \text { to } 4^{\circ} \mathrm{C} \text {, full thickness) }\end{array}$ & $\begin{array}{l}\text { Cooling electricity savings decrease slightly as melt } \\
\text { range increases }\left(15 \% \text { drop in savings from } 0 \text { to } 4^{\circ} \mathrm{C} \text { melt }\right. \\
\text { range for full thickness) }\end{array}$ \\
\hline $\begin{array}{l}\text { Wall-related savings are about .30 to } .35 \mathrm{kWh} / \mathrm{m}^{2} / \mathrm{year} \\
\text { for } \mathrm{S} \text { and } \mathrm{W} .\end{array}$ & $\begin{array}{l}\text { Greater percent reduction in cooling electricity }(60 \%), \\
\text { but only } 0.14 \text { to } 0.19 \mathrm{kWh} / \mathrm{m}^{2} / \mathrm{year} \text { for S and } \mathrm{W}\end{array}$ \\
\hline $\begin{array}{l}\text { Greatest savings in June , saving from February to } \\
\text { October }\end{array}$ & $\begin{array}{l}\text { Greatest savings also in June , saving from } \mathrm{May} \text { to } \\
\text { September }\end{array}$ \\
\hline $\begin{array}{l}\text { Less sensitive to changes in indoor setpoint: savings } \\
\text { vary from } 0.30 \text { to } 0.32 \mathrm{kWh} / \mathrm{m}^{2} / \mathrm{yr} \text { for full thickness and } \\
\text { from } 0.22 \text { to } 0.38 \text { for inner quarter. }\end{array}$ & $\begin{array}{l}\text { More sensitive to changes in indoor setpoint: savings } \\
\text { vary from } 0.12 \text { to } 0.23 \mathrm{kWh} / \mathrm{m}^{2} / \mathrm{yr} \text { for full thickness and } \\
\text { from } 0.05 \text { to } 0.25 \text { for inner quarter. }\end{array}$ \\
\hline
\end{tabular}

During this study some areas for further exploration were identified.

- The impact of a PCM's melt/freeze characteristics, including hysteresis, were explored. This evaluation showed that these characteristics should be known in order to more accurately assess the potential benefits of any PCM application. For one particular PCM (not an optimized PCM for this location), hysteresis caused the savings to decrease by $50 \%$ in Phoenix and by about $10 \%$ in Baltimore. However, experimental results show such behavior may vary, especially for partial melt-freeze cycles, so further experimental investigations are needed. 
- Other locations within a building, in particular an attic location, will experience a different temperature variation, and may be a more effective location for a PCM system. The PCM properties that would optimize the savings for alternate configurations are likely to be different from those that optimize the savings for the wall application.

- The potential impact on heating loads was small for these two climates, but should be investigated in cooler climates. 


\section{References}

1. Tomlinson, J. J., and D. Heberle, 1990, "Analysis of Wallboard Containing a Phase Change Material," Proc. Of the $25^{\text {th }}$ Intersociety Energy conversion Engineering Conference, Vol. 4, Aug. 12-17, 1990, Reno NV

2. Stovall, T. K. and J. J. Tomlinson, WHAT ARE THE POTENTIAL BENEFITS OF INCLUDING LATENT STORAGE IN COMMON WALLBOARD?, Journal of Solar Energy Engineering, November 1995, Vol. 117

3. Peippo, K., P. Kauranen and P.D. Lund, A multi-component PCM wall optimized for passive solar heating. Energy Build., 17 (1991), pp. 259-270

4. Neeper, D.A., Thermal dynamics of wallboard with latent heat storage. Solar Energy, 68 (2000), pp. 393-403

5. Butala, V. and U. Stritlh, Experimental Investigation of PCM Cold Storage, Energy andBuildings, Vol. 41, Iss 3., March 2009, PP 354-359

6. Eicker, U., Cooling Strategies, Summer Comfort and Energy Performance of a Rehabilitated Passive Standard Office Building, Applied Energy, Vol. 87, Iss 6, June 2010, pp 2031-2039

7. Khudhair, A.M. and M. M. Farid, A Review on Energy Conservation in Building Applications with Thermal Storage by Latent Heat Using Phase Change Materials, Energy Conversion and Management, Vol. 45, Iss. 2, January 2004, PP 263-275

8. J. Kosny, D.W. Yarbrough, W. Miller, T. Petrie, P. Childs, A.M. Syed and D. Leuthold, Thermal performance of PCM-enhanced building envelope systems, Thermal Performance of the Exterior Envelopes of Whole Buildings $X$, Proceedings of the ASHRAE/DOE/BTECC Conference, Clear Water Beach, FL, December 2-7 (2007), pp. 1-8

9. Kosny, J., Yarbrough D., and Wilkes K., 2006. "PCM-Enhanced Cellulose Insulation: Thermal Mass in Light-Weight Fibers," International Energy Agency and Department of Energy Ecostock 2006 Conference, Stockton University, May 31, 2006

10. Childs, K.W, 1993, HEATING 7.2 User's Manual, ORNL/TM-12262, Oak Ridge National Laboratory, Oak Ridge, Tennessee

11. Miller, W., Kośny, J., Shrestha, S., Christian, J., Karagiozis, A., Kohler, K., and Dinse, D., Advanced Residential Envelopes for Two Pair of Energy-Saver Homes, ACEEE Summer Conference, 2011

12. Kosny, J., Yarbrough, D., Miller, W., Petrie, T., Childs, P., Syed, A.M., and Leuthold, D., Thermal Performance of PCM-Enhanced Building Envelope Systems, Thermal Performance of the Exterior Envelopes of Whole Buildings $X$, Proceedings of the ASHRAE/DOE/BTECC Conference, Clear Water Beach, FL, December 2-7 (2007)

13. Press, W. H. et al, Numerical Recipes in FORTRAN, Section 10.4: Downhill Simplex Method in Multidimensions, Cambridge University Press, 1992 


\section{Appendix A Material Properties Used in Modeling}

\begin{tabular}{|c|c|c|c|}
\hline Material & Property & Value (SI Units) & Value (English Units) \\
\hline \multirow{3}{*}{ Cellulose } & Conductivity, $\mathrm{k}_{\text {cell }}$ & $0.0446 \mathrm{~W} / \mathrm{m}-\mathrm{K}$ & $0.0258 \mathrm{Btu} / \mathrm{h}-\mathrm{ft}-{ }^{\circ} \mathrm{F}$ \\
\hline & Density, $\rho_{\text {cell }}$ & $54 \mathrm{~kg} / \mathrm{m}^{3}$ & $3.37 \mathrm{lb} / \mathrm{ft}^{3}$ \\
\hline & Specific Heat, $c_{p-c e l l}$ & $1300 \mathrm{~J} / \mathrm{kg}-\mathrm{K}$ & $0.31 \mathrm{Btu} / \mathrm{lb}-{ }^{\circ} \mathrm{F}$ \\
\hline \multirow{3}{*}{ Gypsum } & Conductivity, $\mathrm{k}_{\mathrm{gyp}}$ & $0.16 \mathrm{~W} / \mathrm{m}-\mathrm{K}$ & $0.0924 \mathrm{Btu} / \mathrm{h}-\mathrm{ft}-{ }^{\circ} \mathrm{F}$ \\
\hline & Density, $\rho_{\text {gyp }}$ & $640 \mathrm{~kg} / \mathrm{m}^{3}$ & $40.0 \mathrm{lb} / \mathrm{ft}^{3}$ \\
\hline & Specific Heat, $c_{p-g y p}$ & $1150 \mathrm{~J} / \mathrm{kg}-\mathrm{K}$ & $0.27 \mathrm{Btu} / \mathrm{lb}-^{\circ} \mathrm{F}$ \\
\hline \multirow{3}{*}{ Siding } & Conductivity, $\mathrm{k}_{\text {sid }}$ & $0.12 \mathrm{~W} / \mathrm{m}-\mathrm{K}$ & $0.0693 \mathrm{Btu} / \mathrm{h}-\mathrm{ft}-{ }^{\circ} \mathrm{F}$ \\
\hline & Density, $\rho_{\text {sid }}$ & $545 \mathrm{~kg} / \mathrm{m}^{3}$ & $34.0 \mathrm{lb} / \mathrm{ft}^{3}$ \\
\hline & Specific Heat, $c_{p-s i d}$ & $1590 \mathrm{~J} / \mathrm{kg}-\mathrm{K}$ & $0.38 \mathrm{Btu} / \mathrm{lb}-^{\circ} \mathrm{F}$ \\
\hline \multirow{3}{*}{ Wood $2 \times 6$} & Conductivity, $\mathrm{k}_{\text {sid }}$ & $4.35 \mathrm{~W} / \mathrm{m}-\mathrm{K}$ & $2.51 \mathrm{Btu} / \mathrm{h}-\mathrm{ft}-{ }^{\circ} \mathrm{F}$ \\
\hline & Density, $\rho_{\text {sid }}$ & $400 \mathrm{~kg} / \mathrm{m}^{3}$ & $25.0 \mathrm{lb} / \mathrm{ft}^{3}$ \\
\hline & Specific Heat, $c_{p-s i d}$ & $2130 \mathrm{~J} / \mathrm{kg}-\mathrm{K}$ & $0.51 \mathrm{Btu} / \mathrm{lb}-{ }^{\circ} \mathrm{F}$ \\
\hline \multirow{2}{*}{ PCM } & Specific Heat, $C_{p-P C M}$ & $1481 \mathrm{~J} / \mathrm{kg}-\mathrm{K}$ & $0.35 \mathrm{Btu} / \mathrm{lb}-{ }^{\circ} \mathrm{F}$ \\
\hline & Latent Heat, $L_{P C M}$ & $1.7 \times 10^{5} \mathrm{~J} / \mathrm{kg}$ & $73.1 \mathrm{Btu} / \mathrm{lb}$ \\
\hline
\end{tabular}




\section{Appendix B Residential Electricity Pricing for Phoenix}

\begin{tabular}{|l|l|}
\hline \multicolumn{1}{|c|}{ Standard } \\
\hline Winter (November - April billing cycles) & Cost per kWh \\
\hline All kWh & $\$ 0.09397$ \\
\hline Summer ( May - October billing cycles) & Cost per kWh \\
\hline 1 - 400 kWh & $\$ 0.09671$ \\
\hline 401 - 800 kWh & $\$ 0.13739$ \\
\hline 801 - 3000 kWh & $\$ 0.16281$ \\
\hline 3001 kWh and up & $\$ 0.17358$ \\
\hline \hline \multicolumn{1}{|c|}{ Time Advantage 7 p.m. - noon } & Cost per kWh \\
\hline Winter (November - April billing cycles) & $\$ 0.19825$ \\
\hline On-peak kWh used (Mon. - Fri., noon - 7 p.m.) & $\$ 0.06124$ \\
\hline $\begin{array}{l}\text { Off-peak kWh used (Mon. - Fri., 7 p.m.- noon and all day Sat. \& Sun., } \\
\text { holidays) }\end{array}$ & Cost per kWh \\
\hline Summer ( May - October billing cycles) & $\$ 0.24445$ \\
\hline On-peak kWh used (Mon. - Fri., noon - 7 p.m.) & $\$ 0.06126$ \\
\hline $\begin{array}{l}\text { Off-peak kWh used (Mon. - Fri., 7 p.m.- noon and all day Sat. \& Sun., } \\
\text { holidays) }\end{array}$ & \\
\hline
\end{tabular}

